\title{
Synthesis of Novel Derivatives Bearing Heterocycles-Tetrahydronaphthalene Conjugates for Antimicrobial and Antiviral Evaluation
}

\author{
Somaia S. Abd El-Karima, Rasha S. Gouhar ${ }^{\text {a* }}$, Mogedda E. \\ Haiba $^{\text {a,b }}$, M. I. El-Zahar ${ }^{\text {a }}$, Ghada E. A. Awad ${ }^{\text {c }}$ and Ola \\ Bagato $^{\mathrm{d}}$ \\ a Therapeutical Chemistry Department, National Research \\ Center, Dokki, Cairo, 12622, Egypt, ${ }^{b}$ Pharmaceutical \\ Chemistry Department, Faculty of Pharmacy, King Saud \\ University, Riyadh 11451, Saudi Arabia, ${ }^{c}$ Chemistry of Natural \\ and Microbial Products Department and ${ }^{d}$ Center of Scientific \\ Excellence for Influenza Viruses, Environmental Research \\ Division, National Research Centre, Dokki , Cairo12622, \\ Egypt.
}

$\mathbf{T}$

HE KEY compound 2-cyano- $N$ '-(2,3-dihydronaphthalen-4(1H)ylidene) acetohydrazide (1) was allowed to react with different aryl diazonium salts and different aldehydes to give the corresponding hydrazone (2a-d) and arylidene derivatives (3a-d). The arylidene derivatives (3a-d) were cyclized with malononitrile, ethylcyanoacetate and/or hydrazine hydrate to give the corresponding derivatives (4, 5 and 6). Moreover, compound 1 was condensed with different substituted isothiocyanates in the presence of chloroacetone, phenacyl bromide and/or ethylbromoacetate to give the thiazole derivatives (810). Compound 10 was coupled with various aryl diazonium salts to get the corresponding 4-oxothiazolidine compounds (11a,b). Furthermore, compound 1 was treated with carbon disulfide in the presence of hydrochloric acid, ethylbromoacetate and dimethyl sulfate to give the mercapto derivatives (12-14). Amino thiazole derivatives (16 and 17) were obtained by cyclization of compound 1 with phenyl isothiocyanate or cyclohexanone in presence of sulfur. These newly synthesized compounds were evaluated as antimicrobial and antiviral activity.

Keywords: Tetrahydronaphthalene, Cyanoacetohydrazide, Oxopyridine, Pyrazole, Thiazole, Thiazolidinone, Antimicrobial and Antiviral activity.

* Corresponding author. E-mail: dr.Rasha_Gouhar@yahoo.com 
The incidence of microbial infection has increased on frightening levels over the world as a result of antimicrobial resistance. Microbial infections are a growing problem in contemporary medicine and the use of antibiotics is common across the world ${ }^{(1)}$. In the past few decades, significant efforts in the diagnosis and treatment of microbial diseases have been accomplished. These efforts led to impressive gains in the treatment of microbial diseases introducing a range of therapeutic strategies in clinical practice. In spite of a large number of antibiotics and chemotherapeutics available for medical use at the same time the emergence of old and new antibiotics resistance created in the last decades a substantial medical need for new classes of antibacterial agents ${ }^{(2)}$. Influenza infections are responsible for over 3 million cases of illness and up to a half of million deaths per year. Although antiviral drugs against influenza infections are available, the emergence of viral resistance to existing antiviral drugs emphasizes the demand for development of new antiviral drugs against influenza infections (3). Identification of novel compounds which treat infectious states more effectively, and which lack side effects associated with current therapies, remains a major challenge in biomedical research ${ }^{(4)}$.

There are several reports in the literature describing the tetrahydronaphthalene derivatives for their various pharmacological activities, including action as nonsteroidal glucocorticoid receptor modulators ${ }^{(5)}$, anticancer ${ }^{(6-8)}$, antimicrobial ${ }^{(9)}$, antifungal $^{(10)}$ and anti-HIV ${ }^{(11,12)}$. The thiazolidinones ring with $\mathrm{C}-2$ and $\mathrm{N}-3$ substituted positions has been incorporated into a broad range of known biologically active compounds as antimicrobial ${ }^{(13)}$, anti-inflammatory (14), anticancer and antiviral activity ${ }^{(15)}$. Also, thiazoles exist in many condensed fused systems that were found to possess a wide range of activity ${ }^{(16)}$.

Moreover, pyrazoles occupy an important position in medicinal chemistry with having a wide range of bioactivities such as antibacterial ${ }^{(17)}$, anticancer ${ }^{(18)}$, antidepressant ${ }^{(19)}$, anticonvulsant ${ }^{(20)}$ and antipyretic ${ }^{(21)}$. A number of hydrazidehydrazone derivatives ${ }^{(22)}$ have been claimed to possess interesting bioactivity such as antibacterial, antifungal ${ }^{(23)}$, anticonvulsant ${ }^{(24)}$, antimalarial ${ }^{(25)}$ and antituberculosis ${ }^{(26)}$ activities.

Different known clinically applied antiviral drugs such as Ritonavir (27), Saquinavir (28), antimicrobial drugs such as Cefditoren (29), Temocillin (30), Sulfaphenazole ${ }^{(31)}$ and antifungal such as Abafungin $^{(32)}$ are bearing thiazole, thiophene saturated quinoline and pyrazole moieties (Fig. 1). Additionally, Nafcillin clinically applied as antimicrobial activity ${ }^{(33,34)}$ and literature survey exhibited that some of the synthesized derivatives comprising tetrahydronaphthalene ring such as compounds $\mathrm{A}^{(11)}$ and $\mathrm{B}^{(35)}$ produced significant antimicrobial activities (Fig. 2). 
<smiles>CC(C)c1nc(CN(C)C(=O)NC(C(=O)NC(Cc2ccccc2)C[C@H](C)[C@H](Cc2ccccc2)NC(=O)OCc2cncs2)C(C)C)cs1</smiles><smiles>C[C@H](CN1CC2CCCCC2C[C@H]1C(=O)NC(C)(C)C)[C@@H](O)Cc1ccccc1</smiles><smiles>CO/N=C(/C(=O)N[C@@H]1C(=O)N2C(C(=O)O)C(/C=C\c3scnc3C)CS[C@H]12)c1csc(N)n1</smiles><smiles>CC[C@]1(NC(=O)C(C(=O)O)c2ccsc2)C(=O)N2[C@@H](C(=O)O)C(C)(C)S[C@]21C</smiles><smiles>Nc1ccc(S(=O)(=O)Nc2ccnn2-c2ccccc2)cc1</smiles><smiles>Cc1ccc(Oc2ccccc2-c2csc(NC3=CCCCN3)n2)c(C)c1</smiles>

Fig. 1. Examples of clinically applied thiazole, thiophene analogues with antiviral or antimicrobial activity.<smiles>CCOc1ccc2ccccc2c1C(=O)N[C@H]1C(=O)N2C(C(=O)O)C(C)(C)S[C@H]12</smiles>

Nafcillin<smiles>[3H]COCn1c(CC2CCCc3ccccc32)c(CC)c(=O)[nH]c1=O</smiles><smiles>COc1ccc2c(c1)CCC(NCCCCl)C2</smiles>

Fig. 2. Examples of clinically applied and synthesized tetrahydronaphthalene analogues with antiviral or antimicrobial activity.

Egypt. J. Chem. 57, No.4 (2014) 
Therefore development of alternative new more effective antimicrobial agents with new modes of action and a broad spectrum of activities is a one of the major challenges in drug discovery. Molecular hybridization involves combining two or more heterocyclic rings in a single molecule wherein combining units are derived from known bioactive molecules. Pharmacophore hybridization is believed to be analogous to conventional combination therapy wherein the two drugs are covalently linked and available as a single entity ${ }^{(36)}$.

In view of the above-mentioned findings, in continuation of our research interest in the synthesis of potentially bioactive heterocyclic compounds with diverse applications through hybridization ${ }^{(37)}$, we report herein the synthesis of a series of tetrahydronaphthalene compined with different heterocyclics through hydrazone linked as target compounds (Fig. 3) and evaluated as antiviral and antimicrobial agents. This combination was suggested to investigate the influence of such hybridization and structure variation on the anticipated biological activities, hoping to add some synergistic biological significance to the target molecules.<smiles>[R][X]=C(C#N)C(=O)NN=C1CCCc2ccccc2/C1=N\NC(=O)c1cn[nH]c1</smiles>

Fig. 3. Examples of the target synthezided tetrahydronaphthalene analogues.

\section{Results and Discussion}

\section{Chemistry}

The reaction sequences employed for synthesis of the target substituted or nonsubstituted heterocyclic and aromatic rings such as oxopyridine, pyrazole, thiazole, thiazolidinone and thioxothiazole are depicted in Schemes 1-3. The key intermediate 2-cyano- $N^{\prime}$-(2,3-dihydronaphthalen-4 (1H)-ylidene) acetohydrazide (1) was synthesized through the condensation of equimolar amounts of $\alpha$-tetralone and 2cyanoacetohydrazide under basic a catalyzed reaction in accordance with the method described in the literature ${ }^{(38)}$. In the present investigation we studied the reactivity of the active methylene group present in cyanoacetohydrazide (1) towards versatile diazonium salts. Thus, the reaction of compound 1 with the appropriate substituted benzenediazonium salts namely; $o$-tolyl diazonium chloride, $p$-bromobenzene diazonium chloride, $m$-nitrobenzene diazonium chloride and/or $o$-carboxylbenzene diazonium chloride afforded the acetohydrazide derivatives $2 \mathrm{a}-\mathrm{d}$, respectively. The ${ }^{1} \mathrm{H}$ NMR spectrum of the derivative $2 \mathrm{a}$ showed the appearance of a singlet signal at $\delta 2.29 \mathrm{ppm}$ corresponding to the methyl protons. The mass spectrum of the compound $2 \mathrm{~b}$ revealed the appearance of the molecular ion peaks at m/e 409, 411 which represents the two isotopic peaks of the bromine atom.

Egypt. J. Chem. 57, No.4 (2014) 
In addition, the reaction of cyanoacetohydrazide (1) with different aldehydes derivatives namely; 4-fluorobenzaldehyde, 5-methylfuran-2-carboxaldehyde, 3,4,5-trimethoxybenzaldehyde, and/or $1 H$-indole-3-carboxaldehyde in ethanol afforded the corresponding acrylohydrazide derivatives 3a-d, respectively. The ${ }^{1} \mathrm{H}$ NMR spectrum of the derivative $3 \mathrm{~b}$ showed the appearance of a singlet signal at $\delta 2.45 \mathrm{ppm}$ corresponding to the methyl protons. Also, ${ }^{13} \mathrm{C}$ NMR spectrum of the same derivative showed a signal at $\delta 13.37 \mathrm{ppm}$ corresponding to the methyl carbon. In addition, ${ }^{1} \mathrm{H}$ NMR spectrum of compound $3 \mathrm{c}$ recorded singlet signals at $\delta 3.62$ and $3.74 \mathrm{ppm}$ referring to the three methoxy groups. The mass spectra of 3a-d revealed the molecular ion peaks at m/e 333, 319, 405 and 354 corresponding to the correct molecular formulae of $3 \mathrm{a}-\mathrm{d}$, respectively.

Further evidence for the structures of acrylohydrazide derivatives 3a-d was obtained through studying their chemical reactivity via some chemical reagents. Thus, cycolocondensation of compounds $3 \mathrm{a}, \mathrm{b}$ with either malononitrile or ethyl cyanoacetate in dioxane and triethylamine as a catalyst afforded pyridine-2-one derivatives $4 \mathrm{a}, \mathrm{b}$ and $5 \mathrm{a}, \mathrm{b}$, respectively. The mass spectra of $4 \mathrm{a}, \mathrm{b}$ revealed the molecular ion peaks at m/e 397 and 383 corresponding to their correct molecular formulae, respectively. The ${ }^{1} \mathrm{H}$ NMR spectrum of the derivative 5a showed triplet and quartet signals at $\delta 1.29$ and $4.33 \mathrm{ppm}$ corresponding to the ester group. Furthermore, 5-amino-3-(substituted)-N'-(2,3-dihydronaphthalen-4(1H)-ylidene)$1 \mathrm{H}$-pyrazole-4-carbohydrazide $6 \mathrm{a}, \mathrm{c}, \mathrm{d}$ were achieved by the cyclocondensation of acrylohydrazide derivatives $3 \mathrm{a}, \mathrm{c}, \mathrm{d}$ with hydrazine hydrate in ethanol. Their IR spectra revealed the appearance of bands at $3108-3430 \mathrm{~cm}^{-1}$ corresponding to $\left(\mathrm{NH}, \mathrm{NH}_{2}\right)$ groups and the disappearance of any band corresponding to $(\mathrm{CN})$ group. Also, the mass spectra of $6 \mathrm{a}, \mathrm{c}, \mathrm{d}$ showed the molecular ion peaks at $\mathrm{m} / \mathrm{e}$ 363,435 and 384 corresponding to the correct molecular formulae of compounds, respectively (Scheme 1).

The synthesis of the new 4-substituted thiazole and thiazolidinone derivatives was carried out by the reaction of an active methylene group with different $\alpha$-halo ketones. Thus, the treatment of the active methylene moiety of cyanoacetohydrazide (1) with phenylisothiocyanate and/or p-methoxy phenylisothiocyanate in dimethylformamide (DMF) containing a catalytic amount of potassium hydroxide led to the unstable intermediate potassium sulfide salt 7 . Then chloroacetone was added to yield 2-cyano-N'- (2,3-dihydronaphthalen-4 (1H)-ylidene)-2- (4-methyl-3(substituted) thiazol-2(3H)-ylidene) acetohydrazide derivatives 8a,b, respectively. The ${ }^{1} \mathrm{H}$ NMR spectrum of the thiazole derivative 8a showed the appearance of a singlet signal at $\delta 2.34 \mathrm{ppm}$ corresponding to the methyl protons and another singlet signal at $\delta 6.11 \mathrm{ppm}$ referring to $\mathrm{CH}$-thiazole moiety. Also, ${ }^{13} \mathrm{C}$ NMR spectrum of the thiazole derivative 8a exhibited signals at $\delta 21.08$ and $100.28 \mathrm{ppm}$ due to the methyl group and $\mathrm{C}_{5}$-thiazole moiety. Moreover, condensation of the intermediate potassium sulfide salt 7 with phenacyl bromide and/or $p$-bromophenacyl bromide produced the corresponding 4-substituted phenyl thiazole derivatives 9a,b, respectively. ${ }^{13} \mathrm{C}$ NMR spectrum of the thiazole derivative $9 \mathrm{a}$ exhibited a signal at $\delta 101.78 \mathrm{ppm}$ referring to 
$\mathrm{C}_{5}$-thiazole moiety. While, ${ }^{1} \mathrm{H}$ NMR spectrum of the thiazole derivative $9 \mathrm{~b}$ showed the appearance of a singlet signal at $\delta 6.87 \mathrm{ppm}$ referring to $\mathrm{CH}$-thiazole moiety. Furthermore, the thiazolidinone derivatives $10 \mathrm{a}, \mathrm{b}$ were obtained by condensation of the intermediate potassium sulfide salt 7 with ethyl bromoacetate. IR spectra of compounds 10a,b showed the appearance of bands at 1741 and $1739 \mathrm{~cm}^{-1}$ corresponding to $(\mathrm{CO})$ of thiazolidinone moiety. ${ }^{1} \mathrm{H}$ NMR spectrum of the thiazolidinone derivative 10a showed the appearance of a singlet signal at $\delta 3.85 \mathrm{ppm}$ corresponding to $\mathrm{CH}_{2}$-thiazolidinone moiety. Coupling of the thiazolidinone derivatives 10a,b with $p$-tolyl diazonium chloride and/or $p$-bromobenzene diazonium chloride led to the 5-hydrazinyl thiazolidinone derivatives $11 \mathrm{a}, \mathrm{b}$, respectively. ${ }^{1} \mathrm{H}$ NMR spectrum of the compound 11a showed the appearance of a singlet signal at $\delta$ $2.46 \mathrm{ppm}$ corresponding to methyl protons and the disappearance of the signal corresponding to $\mathrm{CH}_{2}$ protons of thiazolidinone moiety, (Scheme 2).

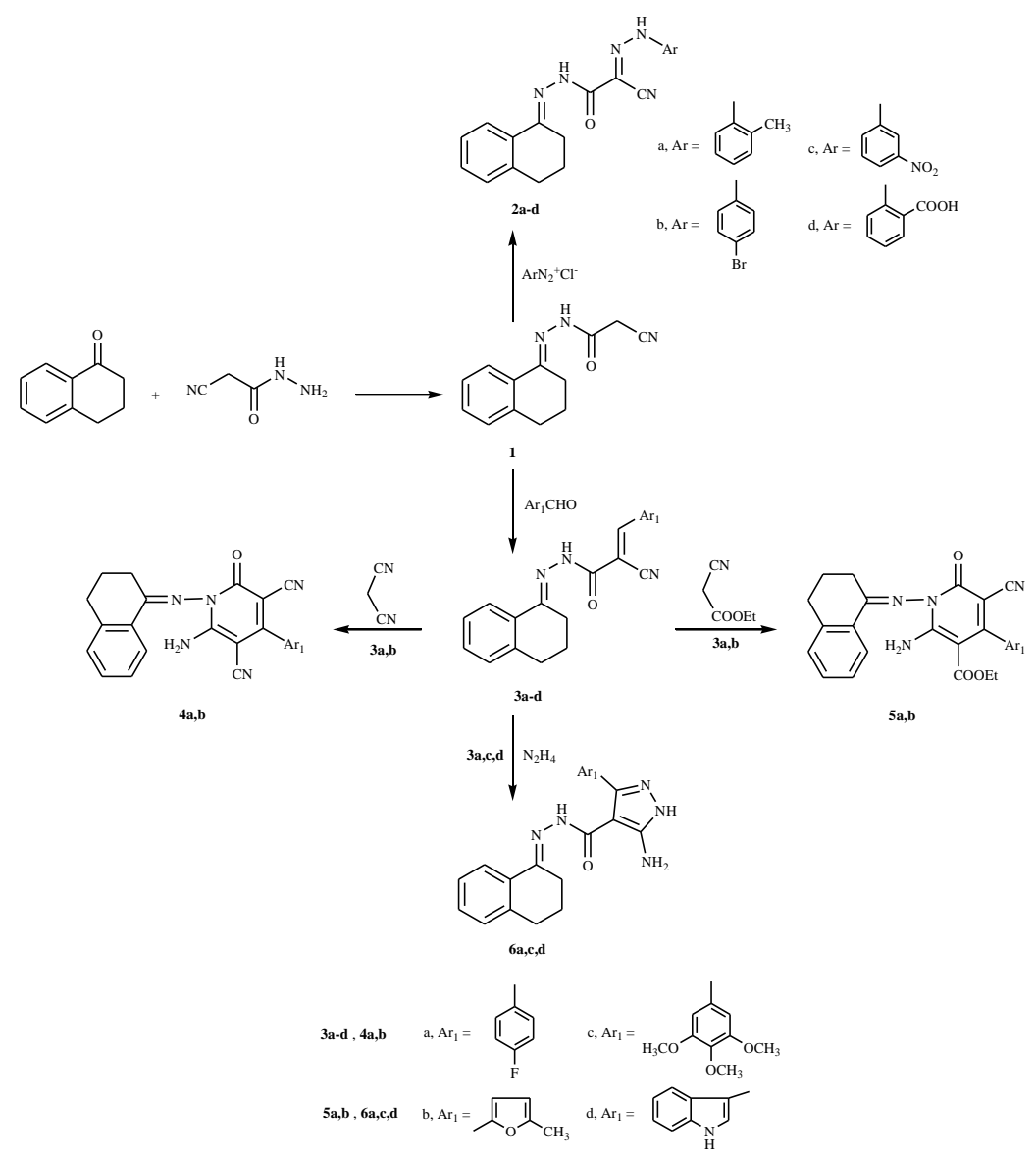

Scheme 1

Egypt. J. Chem. 57, No.4 (2014) 

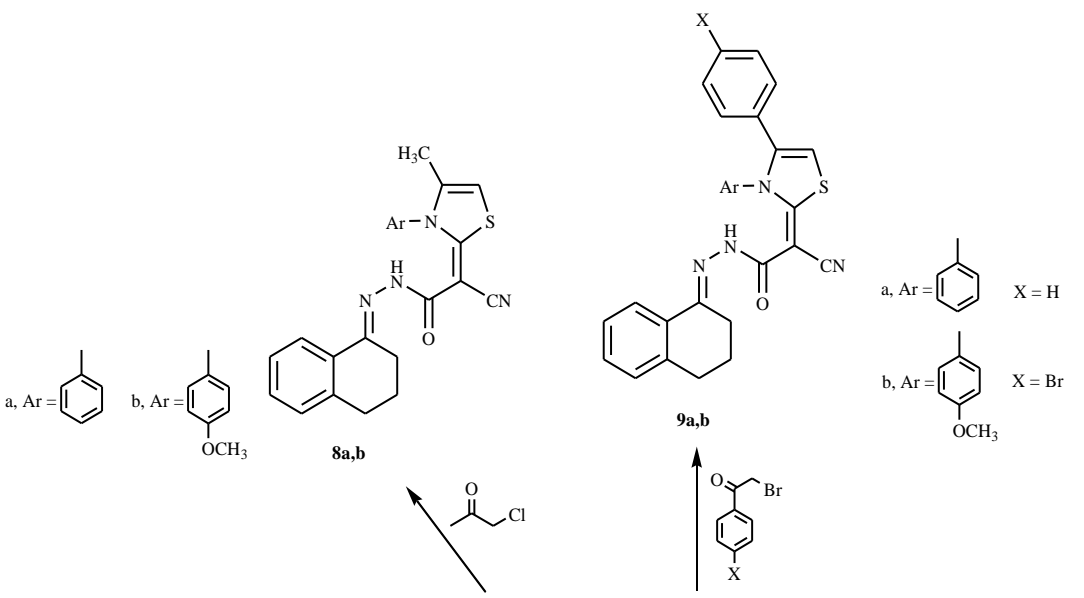

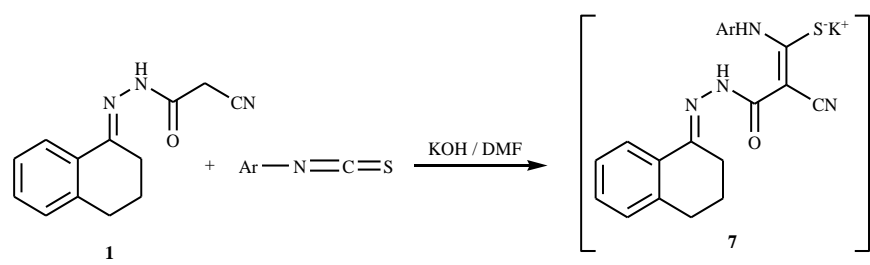<smiles>CCOC(=O)CBr</smiles><smiles>C/C(C(=O)N/N=C1\CCCc2ccccc21)=C1/CCC(=O)N1C</smiles><smiles>[Al][W]1CCCCC1</smiles>

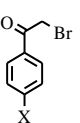

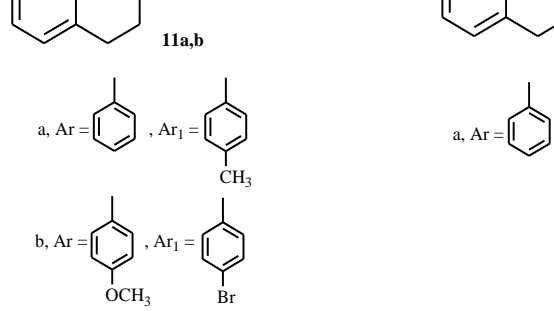

10a,b

Scheme 2

On the other hand, the reaction of cyanoacetohydrazide (1) with carbon disulfide in dimethylformamide (DMF) containing a catalytic amount of potassium hydroxide led to the unstable intermediate potassium sulfide salt 12 which was treated with diluted hydrochloric acid to afford the corresponding dithiol derivative $13 .{ }^{1} \mathrm{H}$ NMR spectrum of compound 13 showed three singlet 
signals at $\delta 10.30,12.72,13.81 \mathrm{ppm}$ referring to $\mathrm{NH}$ and $2 \mathrm{SH}$ groups. While the mass spectrum of the same compound revealed the molecular ion peaks at m/e 303 corresponding to its correct molecular formula. Also, ethyl 2-(2-(2,3dihydronaphthalen-4(1H)- ylideneaminocarbamoyl) -2-cyano-1-mercaptovinylthio) acetate (14) was obtained by the alkylation of the intermediate potassium sulfide salt 12 with ethyl bromoacetate. IR spectrum of compound 14 showed the appearance of a band at $1730 \mathrm{~cm}^{-1}$ corresponding to (CO) ester group. Also, ${ }^{1} \mathrm{H}$ NMR spectrum of compound 14 exhibited the triplet and the quartet signals of the ester group at $\delta 1.37$ and $4.27 \mathrm{ppm}$, respectively, while the $\mathrm{CH}_{2}$ group appeared as a singlet signal at $\delta 3.48 \mathrm{ppm}$. In addition its ${ }^{13} \mathrm{C} N \mathrm{NMR}$ spectrum exhibited signals at $\delta 13.49,34.95$ and 188.19 ppm related to the ester group and another signal at $\delta 60.19 \mathrm{ppm}$ referring to the $\mathrm{CH}_{2}$ group. Ketene $S$, $S$-dithioacetals derivative 15 was prepared by the alkylation of the intermediate potassium sulfide salt 12 with dimethylsulfate. ${ }^{1} \mathrm{H}$ NMR spectrum of compound 15 showed a singlet signal at $\delta 2.48 \mathrm{ppm}$, corresponding to the six protons of the two similar methyl protons, while the singlet signal of the methylene protons of the parent molecule was disappeared. Cyclocondensation of bis(methylthio)acrylohydrazide derivative 15 with hydrazine hydrate and/or phenyl hydrazine in ethanol afforded the corresponding 3-(methylthio) $1 \mathrm{H}$-pyrazole-4carbohydrazide derivatives $16 \mathrm{a}, \mathrm{b}$, respectively. IR spectrum of compound $16 \mathrm{a}$ showed the appearance of bands at $3430,3192 \mathrm{~cm}^{-1}$ corresponding to $(2 \mathrm{NH}$, $\mathrm{NH}_{2}$ ) groups and the disappearance of any band corresponding to $(\mathrm{CN})$ group. While, it's ${ }^{1} \mathrm{H}$ NMR spectrum showed a singlet signal at $\delta 2.47 \mathrm{ppm}$ corresponding to three protons of one methyl group.

Also, condensation of cyanoacetohydrazide (1) with cyclohexanone and elemental sulfur in dioxane and triethylamine as a catalyst afforded the corresponding 4,5,6,7-tetrahydrobenzo[b]thiophene derivative 17. Formation of compound 17 took place according to the method described by Gewald, by the reaction of cyclohexanone with methylene reagents and elemental sulfur ${ }^{(22)}$.

IR spectrum of compound 17 showed the appearance of a broad band centered at $3422 \mathrm{~cm}^{-1}$ corresponding to $\left(\mathrm{NH}, \mathrm{NH}_{2}\right)$ groups and the disappearance of any band corresponding to $(\mathrm{CN})$ group. Moreover, the reaction of cyanoacetohydrazide (1) with phenylisothiocynate and elemental sulfur in dioxane and triethylamine as a catalyst afforded the corresponding 3-phenyl-2thioxothiazole derivative 18. IR spectrum of compound 18 showed the appearance of bands at $3441,3284,3168 \mathrm{~cm}^{-1}$ corresponding to $\left(\mathrm{NH}, \mathrm{NH}_{2}\right)$ groups and $1250 \mathrm{~cm}^{-1}$ corresponding to $(\mathrm{C}=\mathrm{S})$ and the disappearance of any band corresponding to $(\mathrm{CN})$ group. The mass spectra of compounds 17 and 18 revealed the molecular ion peaks at $\mathrm{m} / \mathrm{e} 339$ and 394 corresponding to the correct molecular formulae of compounds 17 and 18, respectively (Scheme 3). 


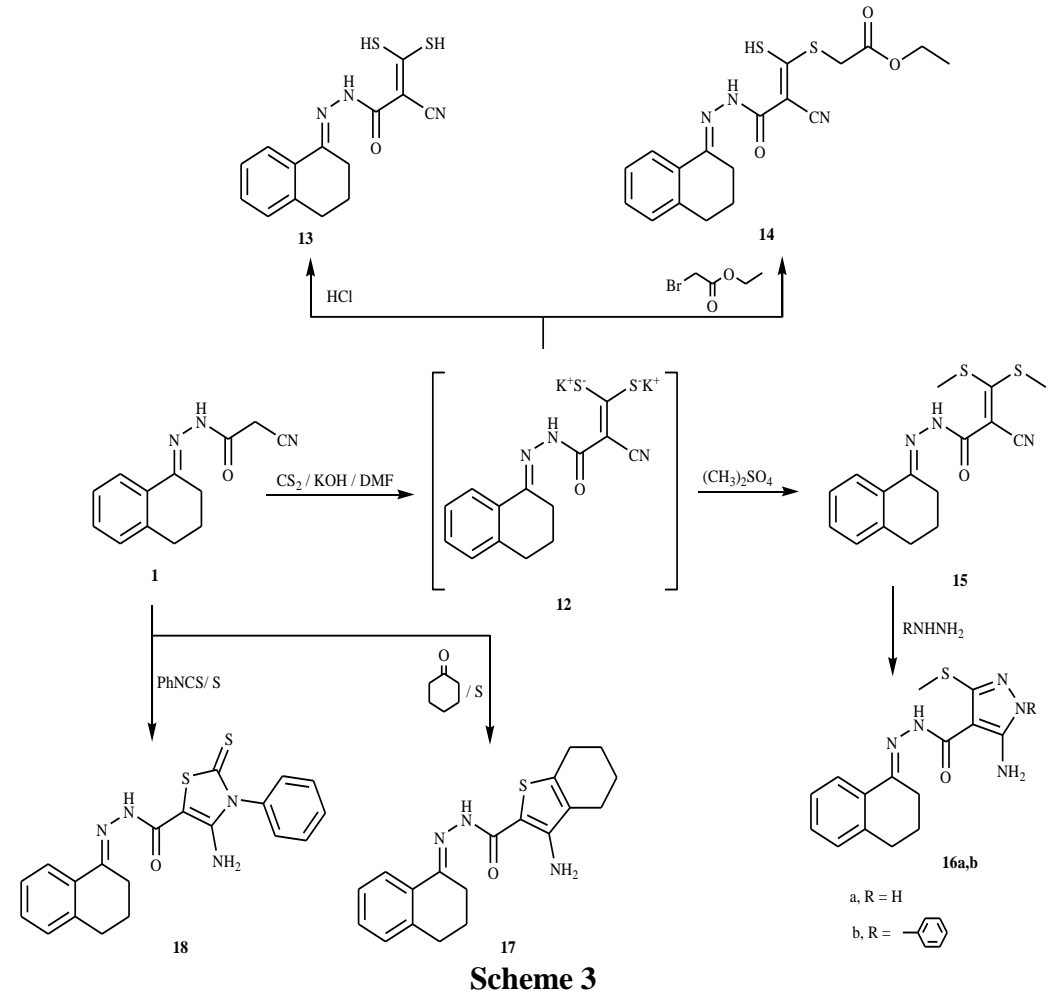

Biological Evaluation

\section{Antimicrobial evaluation}

In this study, 24 compounds out of the newly synthesized compounds were selected as examples to evaluate their antimicrobial activity against a number of Gram positive, Gram negative and fungal strains using Ciprofloxacin and Clotrimazole as standard antibiotic and antifungal drugs. (Table 1) representing the diameter of zones of inhibition $(\mathrm{mm})$ of the tested derivatives, exhibited that the conjugation of the parent tetrahydronaphthalene cyanoacetohydrazide nucleus with 3-nitrophenyl hydrazone side chain (compound 2c) produced the highest broad spectrum antimicrobial activity against the tested Gram positive, Gram negative bacteria with zones of inhibition (ZI) higher than those obtained by the reference Ciprofloxacin (ZI; 27-29 mm, Ciprofloxacin; 20-25mm). At the same time, the replacement of $m$-nitrophenyl ring with benzoic acid moiety (compound 2d) led to a noteworthy drop in the activity against the tested Gram negative bacteria (ZI; 15-20 mm, Ciprofloxacin; 23-25 mm), while its activity against Gram positive bacteria remained higher than the reference drug (ZI; $25-29 \mathrm{~mm}$ ).

Furthermore, the attachment of the parent tetrahydronaphthalene cyanoacetohydrazide moiety with 1-phenyl- $1 H$-pyrazole ring (15b) exhibited an 
approximate equipotent activity to that obtained by Ciprofloxacin against Gram positive and Gram negative bacterial strain (ZI; 16-25 mm). Although slight reduction in the activity against Gram positive bacteria (ZI; 20-21 mm) was obtained upon conjugation of the main nucleus with thiazole ring (compound $9 b$ ), observable reduction in the antibacterial activity against Gram negative bacteria to be moderately active compounds (ZI; 16-18 mm).

Also, the antibacterial data showed that the rest of the tested compounds produced moderate activity against the tested Gram positive and Gram negative bacterial strains. With respect to the antifungal activity, the tested compounds appeared to be moderately active as antifungal agents except compound $2 \mathrm{~d}$ which showed approximate equipotent activity to that obtained by the reference Clotrimazole against the tested yeast (ZI; 28-29 mm, Clotrimazole 29-30 mm). Also, the attachment of the tetrahydronaphthalene cyanoacetohydrazide nucleus to thiazole-2-thione ring system 18 led to gain high anti-yeast and antifungal activity that is approximately equal that gained by the reference Clotrimazole drug. Table 2 represents the minimum inhibitory concentrations (MIC) that shows no growth of the pathological strains. This apparent that compound $2 \mathrm{c}$ produced its activity at MIC twice that of the reference drug Ciprofloxacin (MIC, $50 \mu \mathrm{g} / \mathrm{ml}$ and $25 \mu \mathrm{g} / \mathrm{ml}$ ), while MIC of the same compound against the pathological yeast and fungi are much higher than that of the reference drug. In case of compound $2 \mathrm{~d}$, it showed its efficiency against the tested Gram positive and yeast strains at MIC twice that of the standard Ciprofloxacin and Clotrimazole, while complete insensitivity was observed by Gram negative bacteria. Only $\beta$-megaterium Gram positive bacterial strain showed high sensitivity to compounds $15 \mathrm{a}, \mathrm{b}$ at MIC less than or equal to Ciprofloxacin (MIC, $18 \mu \mathrm{g} / \mathrm{ml}$ and $25 \mu \mathrm{g} / \mathrm{ml}$ ), but the rest of the tested strains showed weak or less sensitivity to both of them. Further modification of the synthesized tetrahydronaphthalene compounds is required to improve their anti microbial activity.

\section{Antiviral evaluation}

Since the scope of this work is to study the antiviral activity of the synthesized compounds, thus all of them were evaluated as antiviral agents $\left(\mathrm{H}_{5} \mathrm{~N}_{1}\right)$. Table 3 represents that all of the tested compounds are safe towards the normal cells. Unfortunately, the obtained data revealed that most of the compounds produced weak to complete inactivity as antiviral agents ( $\%$ of growth inhibition; 0-35\%). Also, it has been observed that moderate antiviral activity (\% of growth inhibition; 40-47 \%) was obtained the analogues carrying the parent tetrahydronaphthalene cyanoacetohydrazide core in attachment with benzoic acid moiety, thiazolidinone ring and mercaptovinylthioacetate side chain 2d, 10b, 14, respectively (Table 4).

Egypt. J. Chem. 57, No.4 (2014) 
TABLE 1. Antimicrobial activity expressed as inhibition diameter zones in millimeters $(\mathrm{mm})$ of the tested compounds against the pathological strains based on well diffusion assay.

\begin{tabular}{|c|c|c|c|c|c|c|c|c|c|}
\hline \multirow[b]{2}{*}{ 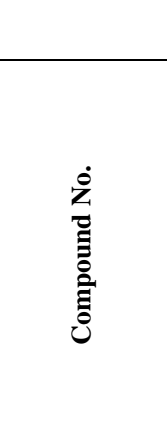 } & \multicolumn{3}{|c|}{ Gram positive bacteria } & \multicolumn{3}{|c|}{ Gram negative bacteria } & \multicolumn{2}{|c|}{ Yeast } & \multirow{2}{*}{ 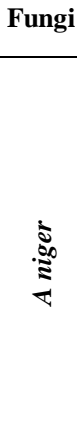 } \\
\hline & 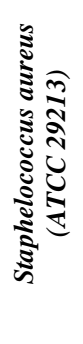 & 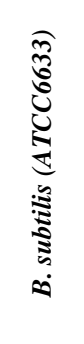 & 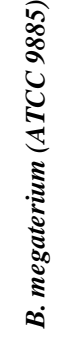 & 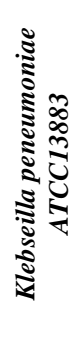 & 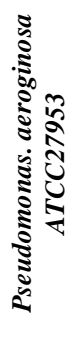 & 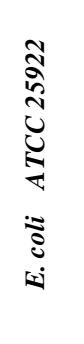 & 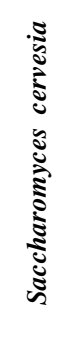 & 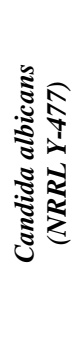 & \\
\hline 1 & 16 & 13 & 15 & 19 & 28 & N.A. & 17 & 12 & 20 \\
\hline $2 \mathrm{a}$ & N.A. & 15 & 16 & 15 & 18 & 12 & 18 & 15 & 20 \\
\hline $2 b$ & 13 & 18 & 20 & N.A. & 16 & 15 & 21 & 18 & 15 \\
\hline $2 \mathrm{c}$ & 27 & 27 & 29 & 22 & 27 & 22 & 22 & 20 & 15 \\
\hline $2 \mathrm{~d}$ & 25 & 27 & 29 & 20 & 15 & 15 & 29 & 28 & 17 \\
\hline $3 \mathrm{a}$ & N.A. & 15 & 15 & 21 & 19 & 25 & 18 & 15 & 18 \\
\hline $3 b$ & N.A. & 17 & 20 & 16 & 19 & 12 & 12 & N.A. & 22 \\
\hline $3 \mathrm{c}$ & N.A. & N.A. & 12 & 21 & 20 & 15 & 18 & 17 & 12 \\
\hline $3 \mathrm{~d}$ & N.A. & 15 & 18 & 24 & 23 & 12 & 18 & 15 & 20 \\
\hline $4 a$ & 15 & 14 & 17 & 18 & 17 & 20 & 23 & 19 & 24 \\
\hline $4 b$ & 23 & 15 & 19 & 20 & 28 & 19 & 18 & 18 & 25 \\
\hline $5 \mathrm{a}$ & 21 & 15 & 16 & 19 & 18 & 16 & 18 & 15 & 22 \\
\hline $5 b$ & 16 & 22 & 25 & 22 & 14 & 23 & 18 & 18 & 20 \\
\hline $8 \mathrm{a}$ & 21 & 21 & 26 & 16 & 16 & 17 & 16 & 12 & 15 \\
\hline $8 b$ & 18 & 12 & 16 & 19 & 14 & 19 & 18 & 18 & 30 \\
\hline $9 \mathrm{a}$ & 12 & 19 & 21 & N.A. & 15 & N.A. & 18 & 15 & 15 \\
\hline $9 b$ & 21 & 20 & 21 & 17 & 18 & 16 & 25 & 17 & 20 \\
\hline $10 \mathrm{~b}$ & 18 & 18 & 18 & 17 & 13 & 16 & 12 & N.A. & 16 \\
\hline $11 \mathrm{a}$ & 12 & N.A. & 12 & 16 & 18 & 16 & 15 & 12 & 22 \\
\hline $11 \mathrm{~b}$ & 12 & 12 & 16 & 19 & 20 & 16 & 19 & 15 & 17 \\
\hline $15 \mathrm{a}$ & 16 & 16 & 18 & 16 & 12 & 12 & 16 & 15 & N.A. \\
\hline $15 \mathrm{~b}$ & 15 & 15 & 18 & 20 & 16 & 22 & 14 & 15 & N.A. \\
\hline 16 & 12 & 15 & 15 & 17 & 16 & 18 & 16 & 15 & N.A. \\
\hline 17 & 15 & 18 & 20 & 17 & 15 & 16 & 28 & 25 & 38 \\
\hline Ciprofloxacin & 20 & 22 & 24 & 25 & 24 & 23 & N.A. & N.A. & N.A. \\
\hline Clotrimazole & N.A. & N.A. & N.A. & N.A. & N.A. & N.A. & 30 & 29 & 30 \\
\hline
\end{tabular}

The experiment was carried out in triplicate and the average zone of inhibition was calculated.

Egypt. J. Chem. 57, No.4 (2014) 
TABLE 2. Minimum inhibitory concentration $(\mu \mathrm{g} / \mathrm{ml})$ against the pathological strains based on two fold serial dilution technique.

\begin{tabular}{|c|c|c|c|c|c|c|c|c|c|}
\hline \multirow[b]{2}{*}{ 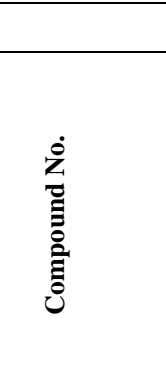 } & \multicolumn{3}{|c|}{ Gram positive bacteria } & \multicolumn{3}{|c|}{ Gram negative bacteria } & \multicolumn{2}{|c|}{ Yeast } & \multirow{2}{*}{ 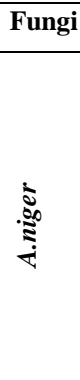 } \\
\hline & 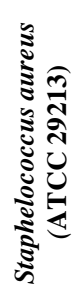 & 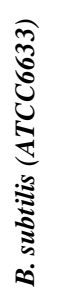 & 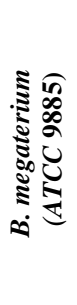 & 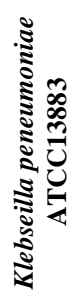 & 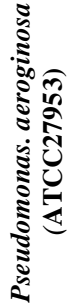 & 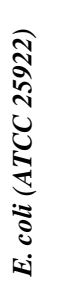 & 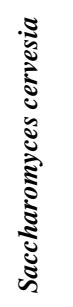 & 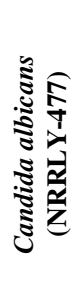 & \\
\hline 1 & 200 & N.A. & N.A. & 200 & 50 & N.A. & 200 & N.A. & 200 \\
\hline $2 \mathrm{a}$ & N.A. & N.A. & 200 & N.A. & 200 & N.A. & 200 & N.A. & 200 \\
\hline $2 \mathrm{~b}$ & N.A. & 200 & 200 & N.A. & 200 & N.A. & 200 & 200 & N.A. \\
\hline $2 \mathrm{c}$ & 50 & 50 & 50 & 50 & 50 & 100 & 100 & 200 & N.A. \\
\hline $2 \mathrm{~d}$ & 100 & 50 & 50 & 200 & N.A. & N.A. & 50 & 50 & 200 \\
\hline $3 a$ & N.A. & N.A. & N.A. & 200 & 200 & 25 & 200 & N.A. & 200 \\
\hline $3 b$ & N.A. & 200 & 200 & 200 & 200 & N.A. & N.A. & N.A. & 200 \\
\hline $3 \mathrm{c}$ & N.A. & N.A. & N.A. & 200 & 200 & N.A. & 200 & 200 & N.A. \\
\hline $3 d$ & N.A. & N.A. & 200 & 100 & 100 & N.A. & 200 & N.A. & 200 \\
\hline $4 a$ & N.A. & N.A. & 200 & 200 & 200 & 200 & 100 & 200 & 50 \\
\hline $4 b$ & 100 & N.A. & 200 & 200 & 100 & 200 & 200 & 100 & 50 \\
\hline $5 a$ & 200 & N.A. & 200 & 200 & 200 & 200 & 200 & N.A. & 200 \\
\hline $5 b$ & N.A. & N.A. & 200 & 200 & 200 & 200 & N.A. & N.A. & N.A. \\
\hline $8 \mathrm{a}$ & 200 & 200 & 100 & 200 & 200 & 200 & 200 & N.A. & N.A. \\
\hline $8 b$ & 200 & N.A. & 200 & 200 & N.A. & 200 & 200 & 200 & 50 \\
\hline $9 a$ & N.A. & 200 & 200 & N.A. & N.A. & N.A. & 200 & N.A. & N.A. \\
\hline $9 b$ & 200 & 200 & 200 & 200 & 200 & 200 & 100 & 200 & 200 \\
\hline $10 \mathrm{~b}$ & 200 & 200 & 200 & 200 & N.A. & 200 & N.A. & N.A. & 200 \\
\hline $11 \mathrm{a}$ & N.A. & N.A. & N.A. & 200 & 200 & 200 & N.A. & N.A. & 200 \\
\hline $11 \mathrm{~b}$ & N.A. & N.A. & 200 & 200 & 200 & 200 & 200 & N.A. & 200 \\
\hline $15 \mathrm{a}$ & 200 & 200 & 18 & 200 & N.A. & N.A. & 200 & N.A. & N.A. \\
\hline $15 b$ & 200 & 100 & 25 & 200 & N.A. & 100 & 200 & 200 & 200 \\
\hline 16 & N.A. & N.A. & N.A. & 200 & 200 & 200 & 200 & N.A. & N.A. \\
\hline 17 & N.A. & 200 & 200 & 200 & N.A. & 200 & 50 & 50 & 50 \\
\hline Ciprofloxacin & 25 & 25 & 25 & 25 & 25 & 25 & N.A. & N.A. & N.A. \\
\hline Clotrimazole & N.A. & N.A. & N.A. & N.A. & N.A. & N.A. & 25 & 25 & 25 \\
\hline
\end{tabular}

Egypt. J. Chem. 57, No.4 (2014) 
TABLE 3. Cytotoxic effect of the tested compounds measured by MTT.

\begin{tabular}{|c|c|c|c|}
\hline Compound No. & $\mathbf{C C}_{\mathbf{5 0}}(\boldsymbol{\mu g} / \boldsymbol{\mu L})$ & Compound No. & $\mathbf{C C}_{\mathbf{5 0}}(\boldsymbol{\mu g} / \boldsymbol{\mu L} \mathbf{)}$ \\
\hline 1 & 130 & $8 \mathrm{a}$ & 168 \\
\hline $2 \mathrm{a}$ & 87 & $8 \mathrm{~b}$ & 121 \\
\hline $2 \mathrm{~b}$ & 153 & $9 \mathrm{a}$ & 261 \\
\hline $2 \mathrm{c}$ & 51 & $9 \mathrm{~b}$ & 133 \\
\hline $2 \mathrm{~d}$ & 211.5 & $10 \mathrm{a}$ & 136 \\
\hline $3 \mathrm{a}$ & 159 & $10 \mathrm{~b}$ & 216 \\
\hline $3 \mathrm{~b}$ & 185 & $11 \mathrm{a}$ & 148 \\
\hline $3 \mathrm{c}$ & 201 & $11 \mathrm{~b}$ & 308 \\
\hline $3 \mathrm{~d}$ & 198 & 13 & 237 \\
\hline $4 \mathrm{a}$ & 404 & 14 & 107.5 \\
\hline $4 \mathrm{~b}$ & 182 & 15 & 137 \\
\hline $5 \mathrm{a}$ & 208 & $16 \mathrm{a}$ & 683 \\
\hline $5 \mathrm{~b}$ & 185 & $16 \mathrm{~b}$ & 289.5 \\
\hline $6 \mathrm{a}$ & 177 & 17 & \\
\hline $6 \mathrm{c}$ & 138 & 18 & \\
\hline $6 \mathrm{~d}$ & 164.5 & & \\
\hline
\end{tabular}

TABLE 4. Antiviral activity (H5N1) measured using Plaque reduction assay.

\begin{tabular}{|c|c|c|c|c|}
\hline \multirow[t]{3}{*}{$\begin{array}{c}\text { Compound } \\
\text { No. }\end{array}$} & $\begin{array}{c}\text { Conc. } \mu \mathrm{g} / \\
\mu \mathrm{l}\end{array}$ & $\begin{array}{l}\text { Initial viral } \\
\text { count }\end{array}$ & $\begin{array}{c}\text { Viral count } \\
\text { (PFU/ml) }\end{array}$ & $\begin{array}{c}\% \text { of } \\
\text { Inhibition }\end{array}$ \\
\hline & 50 & \multirow{2}{*}{$0.65 \times 10^{10}$} & $0.65 \times 10^{10}$ & 0 \\
\hline & 75 & & $0.65 \times 10^{10}$ & 0 \\
\hline \multirow{2}{*}{$2 \mathrm{a}$} & 50 & \multirow{2}{*}{$1.43 \times 10^{10}$} & $1.28 \times 10^{10}$ & 10 \\
\hline & 75 & & $1.02 \times 10^{10}$ & 29 \\
\hline \multirow{2}{*}{$2 b$} & 50 & \multirow{2}{*}{$0.90 \times 10^{10}$} & $0.73 \times 10^{10}$ & 19 \\
\hline & 75 & & $0.73 \times 10^{10}$ & 19 \\
\hline \multirow{2}{*}{$2 \mathrm{c}$} & 25 & \multirow{2}{*}{$0.82 \times 10^{10}$} & $0.70 \times 10^{10}$ & 15 \\
\hline & 50 & & $0.70 \times 10^{10}$ & 15 \\
\hline \multirow{2}{*}{$2 d$} & 50 & \multirow{2}{*}{$0.95 \times 10^{10}$} & $0.51 \times 10^{10}$ & 46 \\
\hline & 75 & & $0.51 \times 10^{10}$ & 46 \\
\hline \multirow{2}{*}{$3 a$} & 50 & \multirow{2}{*}{$1.05 \times 10^{10}$} & $0.9 \times 10^{10}$ & 14 \\
\hline & 75 & & $0.8 \times 10^{10}$ & 24 \\
\hline \multirow{2}{*}{$3 b$} & 50 & \multirow{2}{*}{$0.85 \times 10^{10}$} & $0.85 \times 10^{10}$ & 0 \\
\hline & 75 & & $0.77 \times 10^{10}$ & 9 \\
\hline \multirow[t]{2}{*}{$3 c$} & 50 & \multirow{2}{*}{$1.33 \times 10^{10}$} & $1.33 \times 10^{10}$ & 0 \\
\hline & 75 & & $1.03 \times 10^{10}$ & 22.5 \\
\hline \multirow{2}{*}{$3 d$} & 50 & \multirow{2}{*}{$1.27 \times 10^{10}$} & $1.19 \times 10^{10}$ & 6 \\
\hline & 75 & & $1 \times 10^{10}$ & 21 \\
\hline \multirow{2}{*}{$4 a$} & 50 & \multirow{2}{*}{$1.20 \times 10^{10}$} & $1.20 \times 10^{10}$ & 0 \\
\hline & 75 & & $1.20 \times 10^{10}$ & 0 \\
\hline \multirow[t]{2}{*}{$4 b$} & 50 & \multirow{2}{*}{$0.95 \times 10^{10}$} & $0.95 \times 10^{10}$ & 0 \\
\hline & 75 & & $0.93 \times 10^{10}$ & 2 \\
\hline
\end{tabular}


TABLE 4 Cont.

\begin{tabular}{|c|c|c|c|c|}
\hline $\begin{array}{l}\text { Compound } \\
\text { No. }\end{array}$ & $\begin{array}{c}\text { Conc. } \mu \mathrm{g} / \\
\mu \mathrm{l}\end{array}$ & $\begin{array}{c}\text { Initial viral } \\
\text { count }\end{array}$ & $\begin{array}{c}\text { Viral count } \\
\text { (PFU/ml) }\end{array}$ & $\begin{array}{c}\% \text { of } \\
\text { Inhibition }\end{array}$ \\
\hline \multirow{2}{*}{$5 a$} & 50 & \multirow{2}{*}{$1.20 \times 10^{10}$} & $0.90 \times 10^{10}$ & 25 \\
\hline & 75 & & $0.90 \times 10^{10}$ & 25 \\
\hline \multirow{2}{*}{$5 b$} & 50 & \multirow{2}{*}{$0.90 \times 10^{10}$} & $0.90 \times 10^{10}$ & 0 \\
\hline & 75 & & $0.67 \times 10^{10}$ & 25.5 \\
\hline \multirow{2}{*}{$6 a$} & 50 & \multirow{2}{*}{$0.95 \times 10^{10}$} & $0.77 \times 10^{10}$ & 19 \\
\hline & 75 & & $0.65 \times 10^{10}$ & 31.5 \\
\hline \multirow{2}{*}{$6 c$} & 50 & \multirow{2}{*}{$0.80 \times 10^{10}$} & $0.66 \times 10^{10}$ & 17.5 \\
\hline & 75 & & $0.66 \times 10^{10}$ & 17.5 \\
\hline \multirow{2}{*}{$6 d$} & 50 & \multirow{2}{*}{$1.20 \times 10^{10}$} & $0.85 \times 10^{10}$ & 29 \\
\hline & 75 & & $0.78 \times 10^{10}$ & 35 \\
\hline \multirow{2}{*}{$8 \mathrm{a}$} & 50 & \multirow{2}{*}{$1.20 \times 10^{10}$} & $1.20 \times 10^{10}$ & 0 \\
\hline & 75 & & $1.16 \times 10^{10}$ & 3 \\
\hline \multirow{2}{*}{$8 b$} & 50 & \multirow{2}{*}{$0.85 \times 10^{10}$} & $0.80 \times 10^{10}$ & 6 \\
\hline & 75 & & $0.80 \times 10^{10}$ & 6 \\
\hline \multirow{2}{*}{$9 a$} & 50 & \multirow{2}{*}{$0.65 \times 10^{10}$} & $0.65 \times 10^{10}$ & 0 \\
\hline & 75 & & $0.65 \times 10^{10}$ & 0 \\
\hline \multirow{2}{*}{$9 b$} & 50 & \multirow{2}{*}{$0.82 \times 10^{10}$} & $0.66 \times 10^{10}$ & 19.5 \\
\hline & 75 & & $0.66 \times 10^{10}$ & 19.5 \\
\hline \multirow{2}{*}{$10 \mathrm{a}$} & 50 & \multirow{2}{*}{$1.07 \times 10^{10}$} & $0.95 \times 10^{10}$ & 11 \\
\hline & 75 & & $0.95 \times 10^{10}$ & 11 \\
\hline \multirow{2}{*}{$10 \mathrm{~b}$} & 50 & \multirow{2}{*}{$1.10 \times 10^{10}$} & $0.95 \times 10^{10}$ & 14 \\
\hline & 75 & & $0.66 \times 10^{10}$ & 40 \\
\hline \multirow{2}{*}{$11 \mathrm{a}$} & 50 & \multirow{2}{*}{$1.43 \times 10^{10}$} & $1.35 \times 10^{10}$ & 5.5 \\
\hline & 75 & & $1.13 \times 10^{10}$ & 21 \\
\hline \multirow{2}{*}{$11 \mathrm{~b}$} & 50 & \multirow{2}{*}{$1.27 \times 10^{10}$} & $1.05 \times 10^{10}$ & 17 \\
\hline & 75 & & $1.05 \times 10^{10}$ & 17 \\
\hline & 50 & $080 \times 10^{10}$ & $0.70 \times 10^{10}$ & 12.5 \\
\hline 13 & 75 & $0.80 \times 10^{10}$ & $0.57 \times 10^{10}$ & 29 \\
\hline 14 & 50 & $08 \times 10^{10}$ & $0.42 \times 10^{10}$ & 47.5 \\
\hline 14 & 75 & $0.80 \times 10^{0}$ & $0.42 \times 10^{10}$ & 47.5 \\
\hline 15 & 50 & $08=\mathbf{Y} 10$ & $0.85 \times 10^{10}$ & 0 \\
\hline 15 & 75 & $0.85 \times 10^{10}$ & $0.83 \times 10^{10}$ & 2 \\
\hline & 50 & $105 \times 10^{10}$ & $1 \times 10^{10}$ & 5 \\
\hline $16 \mathrm{a}$ & 75 & $1.05 \times 10^{10}$ & $0.82 \times 10^{10}$ & 22 \\
\hline $16 \mathrm{~h}$ & 50 & $132 \times 10^{10}$ & $1.22 \times 10^{10}$ & 8 \\
\hline $16 b$ & 75 & $1.33 \times 10^{\circ}$ & $1.05 \times 10^{10}$ & 21 \\
\hline 17 & 50 & $10 Y=10$ & $0.90 \times 10^{10}$ & 18 \\
\hline 17 & 75 & $1.10 \times 10^{10}$ & $0.89 \times 10^{10}$ & 19 \\
\hline & 50 & $107 \mathrm{Y} 10$ & $0.82 \times 10^{10}$ & 23 \\
\hline 18 & 75 & $1.07 \times 10^{10}$ & $0.82 \times 10^{10}$ & 23 \\
\hline
\end{tabular}

Egypt. J. Chem. 57, No.4 (2014) 


\section{Conclusion}

This work deals with synthesis of novel derivatives bearing tetrahydronaphthalene moiety conjugated with various side chains and heterocycles such as substituted pyrazole and/ or substituted thiazole ring systems via cyanoacetohydrazide linkage using 2-cyano- $N$ '-(2,3-dihydronaphthalen-4 (1H)ylidene) acetohydrazide (1) as a key starting compound. Antibacterial and antifungal evaluation exhibited that the conjugation of the parent tetrahydronaphthalene cyanoacetohydrazide moiety with 3-nitrophenyl or benzoic acid hydrazone side chain (compounds 2c, 2d, respectively) or with 1-phenyl-1H-pyrazole ring (compound 15b) produced the highest broad spectrum antibacterial activity against the tested Gram positive and Gram negative bacteria. On the other hand, the attachment of the tetrahydronaphthalene cyanoacetohydrazide nucleus to thiazole-2-thione ring system (compound 18) led to gain high anti-yeast and antifungal activity that is approximately equal that gained by the reference Clotrimazole drug. Compound $2 \mathrm{~d}$ showed potent dual activity as antibacterial and antifungal agent. Antiviral evaluation of the novel derivatives exhibited that these derivatives produced moderate to weak activity. More structural modifications are required to improve their antimicrobial potency.

\section{Chemistry}

\section{Experimental}

All melting points are uncorrected and were taken in open capillary tubes using Electrothermal apparatus 9100. Elemental microanalyses were carried out at Microanalytical Unit, Central Services Laboratory, National Research Centre, Dokki, Cairo, Egypt, using Vario Elementar and were found within $\pm 0.4 \%$ of the theoretical values. Infrared spectra were recorded on a Jasco FT/IR-6100, Fourier transform, Infrared spectrometer at $\mathrm{cm}^{-1}$ scale using $\mathrm{KBr}$ disc technique at Central Services Laboratory, National Research Centre, Dokki, Cairo, Egypt. ${ }^{1} \mathrm{H}$ NMR and ${ }^{13} \mathrm{C}$ NMR spectra were determined by using a JEOL AS-500 NMR spectrometer at Central Services Laboratory, National Research Centre, Dokki, Cairo, Egypt, chemical shifts are expressed in $\delta(\mathrm{ppm})$ downfield from TMS as an internal standard. The mass spectra were measured with a GC MSQp1000EX Shimadzu, Cairo University, Cairo, Egypt. Follow up of the reactions and checking the purity of the compounds were made by TLC on silica gelprecoated aluminium sheets (Type 60, F 254, Merck, Darmstadt, Germany) using chloroform/ methanol (10:1, v/v) and the spots were detected by exposure to UV lamp at $\lambda_{254}$ nanometer for few seconds and by iodine vapor. The chemical names given for the prepared compounds are according to the IUPAC system.

2-Cyano-N'-(2,3-dihydronaphthalen-4 (1H)-ylidene) acetohydrazide (1) was prepared according to the reported method ${ }^{(38)}$.

General procedure for the synthesis of 2-(2-(substituted)hydrazono)-2-cyano-N'-(2,3dihydronaphthalen-4(1H)-ylidene)acetohydrazide (2a-c) and 2-(amino-2-cyano-2hydrazonoe- $N^{\prime}-(2,3-$ dihydronaphthalen-4 (1H)-ylidene) aceto)benzoic acid (2d)

To a cold solution of cyanoacetohydrazide 1 ( $2.27 \mathrm{~g}, 0.01 \mathrm{~mol})$ in ethanol (20 $\mathrm{ml})$ containing sodium acetate $(3.0 \mathrm{~g})$, the appropriate substituted 
benzenediazonium salt $(0.01 \mathrm{~mol})$ [prepared by adding sodium nitrite $(1.6 \mathrm{~g}, 0.02$ $\mathrm{mol})$ in water $(8 \mathrm{ml})$ to a cold solution of either of the appropriate substitute aniline namely; $o$-toluidine, $p$-bromoaniline, $m$-nitroaniline and/or $o$ aminobenzoic acid in the appropriate amount of hydrochloric acid] was added with continuous stirring for $2 \mathrm{hr}$. The formed precipitate was filtered, washed several times with water, dried and recrystallized from the proper solvent to give the title compounds $2 \mathrm{a}-\mathrm{d}$.

2-(2-o-Tolylhydrazono) -2-cyano- $N^{\prime}-(2,3$-dihydronaphthalen-4 (1H)-ylidene) acetohydrazide $(2 a)$

Yield $85 \%$, yellow powder (from ethanol), mp. $182-183^{\circ} \mathrm{C}$; IR $\left(\mathrm{KBr}, \mathrm{cm}^{-1}\right)$ : 3435, 3363 (2NH), 3050 (CH arom.), 2952, 2851 (CH aliph.), 2213 (CN), 1664 $(\mathrm{C}=\mathrm{O}), 1587(\mathrm{C}=\mathrm{N}) ;{ }^{1} \mathrm{H}$ NMR $\left(\mathrm{DMSO}_{6}\right): \delta 1.80-1.83\left(\mathrm{~m}, 2 \mathrm{H}, \mathrm{CH}_{2}\right), 2.29(\mathrm{~s}$, $\left.3 \mathrm{H}, \mathrm{CH}_{3}\right), 2.39-2.49\left(\mathrm{~m}, 2 \mathrm{H}, \mathrm{CH}_{2}\right), 2.71-2.77\left(\mathrm{~m}, 2 \mathrm{H}, \mathrm{CH}_{2}\right), 7.08-8.10(\mathrm{~m}, 8 \mathrm{H}$, Ar-H), 10.08, 10.29 (2s, 2H, 2NH, D $2 \mathrm{O}$ exchangeable); ${ }^{13} \mathrm{C}$ NMR (DMSO-d ${ }_{6}$ ): $\delta$ $15.88,20.93,25.05,28.41,107.29,113.50,118.20$, 124.53, 124.75, 125.88, $126.56,127.05,128.22,130.60,130.75,138.71,139.46,139.83,142.21,156.12$; MS, m/z (\%): $345\left[\mathrm{M}^{+}\right](12), 344\left[\mathrm{M}^{+}-1\right](12), 160\left[\mathrm{C}_{10} \mathrm{H}_{12} \mathrm{~N}_{2}\right](27), 106\left[\mathrm{C}_{7} \mathrm{H}_{8} \mathrm{~N}\right]$ (100); Anal. For $\mathrm{C}_{20} \mathrm{H}_{19} \mathrm{~N}_{5} \mathrm{O}$ (345.40): Calcd. (\%) C, 69.55; H, 5.54; N, 20.28; Found (\%): C, 69.68; H, 5.26; N, 20.34.

2-(2-(4-Bromophenyl) hydrazono)-2-cyano -N'-(2,3-dihydronaphthalen-4 (1H) - ylidene) acetohydrazide (2b)

Yield $89 \%$, Orange powder (from ethanol), mp. $145-146^{\circ} \mathrm{C}$; IR $\left(\mathrm{KBr}, \mathrm{cm}^{-1}\right)$ : 3441, 3363 (2NH), 3050 (CH arom.), 2936, 2841 (CH aliph.), 2211 (CN), 1691 $(\mathrm{C}=\mathrm{O}), 1610(\mathrm{C}=\mathrm{N}) ;{ }^{1} \mathrm{H}$ NMR $\left(\mathrm{DMSO}_{-} \mathrm{d}_{6}\right): \delta 1.83-1.87\left(\mathrm{~m}, 2 \mathrm{H}, \mathrm{CH}_{2}\right), 2.46-2.49$ (m, 2H, $\mathrm{CH}_{2}$ ), 2.73-2.77 (m, 2H, $\left.\mathrm{CH}_{2}\right), 7.20-8.07$ (m, 8H, Ar-H), 10.32, 10.57 $\left(2 \mathrm{~s}, 2 \mathrm{H}, 2 \mathrm{NH}, \mathrm{D}_{2} \mathrm{O}\right.$ exchangeable); ${ }^{13} \mathrm{C}$ NMR (DMSO- $\left.d_{6}\right): \delta 20.95,25.24,28.37$, $107.20,110.63,115.74,117.59,124.27,125.82,128.17,129.20,131.42,131.59$, 139.83, 139.85, 140.93, 143.03, 156.02; MS, m/z (\%): 409, $411\left[\mathrm{M}^{+}\right](48,41)$, 408, $410\left[\mathrm{M}^{+}-1\right](42,34), 187\left[\mathrm{C}_{11} \mathrm{H}_{11} \mathrm{~N}_{2} \mathrm{O}\right](66), 116\left[\mathrm{C}_{9} \mathrm{H}_{8}\right]$ (100); Anal. For $\mathrm{C}_{19} \mathrm{H}_{16} \mathrm{BrN}_{5} \mathrm{O}$ (410.27): Calcd. (\%) C, 55.62; H, 3.93; N, 17.07; Found (\%): $\mathrm{C}$, 55.73; H, 4.13; N, 16.85 .

2-(2-(3-Nitrophenyl) hydrazono)-2-cyano- $N^{\prime}$ - (2,3-dihydronaphthalen-4(1H)ylidene) acetohydrazide (2c)

Yield 52\%, yellow powder (from ethanol), mp. 134-135 ${ }^{\circ} \mathrm{C}$; IR $\left(\mathrm{KBr}, \mathrm{cm}^{-1}\right)$ : 3228, 3107 (2NH), 3065 (CH arom.), 2931, 2845 (CH aliph.), 2194 (CN), 1668 $(\mathrm{C}=\mathrm{O}), 1621(\mathrm{C}=\mathrm{N}) ;{ }^{1} \mathrm{H}$ NMR $\left(\mathrm{DMSO}-\mathrm{d}_{6}\right): \delta 1.82-1.85\left(\mathrm{~m}, 2 \mathrm{H}, \mathrm{CH}_{2}\right), 2.48-2.50$ (m, 2H, $\mathrm{CH}_{2}$ ), 2.74-2.76 (m, 2H, $\left.\mathrm{CH}_{2}\right), 7.60-8.26(\mathrm{~m}, 8 \mathrm{H}, \mathrm{Ar}-\mathrm{H}), 10.21,11.14$ (2s, 2H, 2NH, $\mathrm{D}_{2} \mathrm{O}$ exchangeable); MS, m/z (\%): $376\left[\mathrm{M}^{+}\right](14), 377\left[\mathrm{M}^{+}+1\right]$ (11), $91\left[\mathrm{C}_{6} \mathrm{H}_{5} \mathrm{~N}\right]$ (48), $63\left[\mathrm{C}_{5} \mathrm{H}_{3}\right]$ (100); Anal. For $\mathrm{C}_{19} \mathrm{H}_{16} \mathrm{~N}_{6} \mathrm{O}_{3}$ (376.37): Calcd. (\%) C, 60.63; H, 4.28; N, 22.33; Found (\%): C, 60.72; H, 4.07; N, 22.51. 
2-(Amino-2-cyano-2- hydrazono- $N^{\prime}$ - (2,3-dihydronaphthalen-4(1H)-ylidene) aceto) benzoic acid (2d)

Yield 96\%, yellow powder (from ethanol), mp. $233-234^{\circ} \mathrm{C}$; IR $\left(\mathrm{KBr}, \mathrm{cm}^{-1}\right)$ : broad band centered at $3447\left(\mathrm{CO}_{2} \mathrm{H}\right), 3353(\mathrm{NH}), 3065(\mathrm{CH}$ arom.), 2948, 2848 (CH aliph.), $2210(\mathrm{CN}), 1686(\mathrm{C}=\mathrm{O}), 1608(\mathrm{C}=\mathrm{N}) ;{ }^{1} \mathrm{H}$ NMR $\left(\mathrm{DMSO}-\mathrm{d}_{6}\right): \delta 1.84-$ $1.88\left(\mathrm{~m}, 2 \mathrm{H}, \mathrm{CH}_{2}\right), 2.49-2.50\left(\mathrm{~m}, 2 \mathrm{H}, \mathrm{CH}_{2}\right), 2.74-2.78\left(\mathrm{~m}, 2 \mathrm{H}, \mathrm{CH}_{2}\right), 7.21-8.10$ $(\mathrm{m}, 8 \mathrm{H}, \mathrm{Ar}-\mathrm{H}), 10.62,10.95,12.96\left(3 \mathrm{~s}, 3 \mathrm{H}, 2 \mathrm{NH}, \mathrm{CO}_{2} \mathrm{H}, \mathrm{D}_{2} \mathrm{O}\right.$ exchangeable $) ;{ }^{13} \mathrm{C}$ NMR (DMSO-d $)$ ): $\delta$ 20.90, 25.37, 28.28, 110.08, 110.42, 113.85, 115.08, $122.80,124.24,125.72,128.12,128.43,129.22,130.64,131.26,134.21,139.85$, 142.68, 156.00, 169.00; MS, m/z (\%): $375\left[\mathrm{M}^{+}\right]$(28), $376\left[\mathrm{M}^{+}+1\right](7), 187$ $\left[\mathrm{C}_{11} \mathrm{H}_{11} \mathrm{~N}_{2} \mathrm{O}\right](32), 160\left[\mathrm{C}_{10} \mathrm{H}_{12} \mathrm{~N}_{2}\right](13), 129\left[\mathrm{C}_{10} \mathrm{H}_{9}\right](100)$; Anal. For $\mathrm{C}_{20} \mathrm{H}_{17} \mathrm{~N}_{5} \mathrm{O}_{3}$ (375.38): Calcd(\%). C, 63.99; H, 4.56; N, 18.66; Found(\%): C, 63.71; H, 4.82; N, 18.39 .

General procedure for the synthesis of 2-cyano-3-(substituted)-N'-(2,3dihydronaphthalen-4(1H)-ylidene)acrylohydrazide (3a-d)

A mixture of cyanoacetohydrazide $1(2.27 \mathrm{~g}, 0.01 \mathrm{~mol})$ and the appropriate aldehydes derivatives namely; 4-fluorobenzaldehyde, 5-methylfuran-2carboxaldehyde, 3,4,5-trimethoxybenzaldehyde, and/or $1 H$-indole-3-carboxaldehyde $(0.01 \mathrm{~mol})$ in absolute ethanol $(15 \mathrm{ml})$ was refluxed for $3 \mathrm{hr}$. The formed precipitate on cooling was filtered, dried and recrystallized from the proper solvent to give the title compounds $3 \mathrm{a}-\mathrm{d}$.

2-Cyano-3-(4-fluorophenyl)-N'-(2,3-dihydronaphthalen-4(1H)-ylidene) acrylohy drazide (3a)

Yield $65 \%$, yellow powder (from ethanol), mp. $221-222^{\circ} \mathrm{C}$; IR $\left(\mathrm{KBr}, \mathrm{cm}^{-1}\right)$ : 3375 (NH), 3065 (CH arom.), 2946, 2857 (CH aliph.), 2208 (CN), 1687 (C=O), $1595(\mathrm{C}=\mathrm{N})$; ${ }^{1} \mathrm{H}$ NMR $\left(\mathrm{CDCl}_{3}\right): \delta 1.67-1.70\left(\mathrm{~m}, 2 \mathrm{H}, \mathrm{CH}_{2}\right), 1.90-2.01(\mathrm{~m}, 2 \mathrm{H}$, $\left.\mathrm{CH}_{2}\right), 2.68-2.80\left(\mathrm{~m}, 2 \mathrm{H}, \mathrm{CH}_{2}\right), 6.95-8.43(\mathrm{~m}, 9 \mathrm{H}$, olefinic $\mathrm{CH}, \mathrm{Ar}-\mathrm{H}), 9.29$ (s, $1 \mathrm{H}, \mathrm{NH}, \mathrm{D}_{2} \mathrm{O}$ exchangeable); ${ }^{13} \mathrm{C} \mathrm{NMR}\left(\mathrm{CDCl}_{3}\right): \delta 20.53,24.18,28.34,115.60$, $115.90,124.91,125.75,127.41,129.29,132.33,132.44,146.20,152.02,156.21$, 159.22; MS, m/z (\%): $333\left[\mathrm{M}^{+}\right]$(33), $332\left[\mathrm{M}^{+}-1\right]$ (39), 131[C $\left.\mathrm{C}_{10} \mathrm{H}_{11}\right]$ (100); Anal. For $\mathrm{C}_{20} \mathrm{H}_{16} \mathrm{FN}_{3} \mathrm{O}$ (333.36): Calcd. (\%) C, 72.06; H, 4.84; N, 12.61; Found(\%): C, $72.29 ; \mathrm{H}, 4.65 ; \mathrm{N}, 12.43$.

2-Cyano-N'- (2,3-dihydronaphthalen-4 (1H)-ylidene)-3- (5-methylfuran-2-yl) acrylohydrazide (3b)

Yield $68 \%$, reddish brown powder (from ethanol), mp. $201-202^{\circ} \mathrm{C}$; IR $(\mathrm{KBr}$, $\mathrm{cm}^{-1}$ ): $3361(\mathrm{NH}), 3040$ (CH arom.), 2952, 2937, 2874 (CH aliph.), $2207(\mathrm{CN})$, $1681(\mathrm{C}=\mathrm{O}), 1609(\mathrm{C}=\mathrm{N}) ;{ }^{1} \mathrm{H}$ NMR $\left(\mathrm{CDCl}_{3}\right): \delta 1.97-2.01\left(\mathrm{~m}, 2 \mathrm{H}, \mathrm{CH}_{2}\right), 2.45(\mathrm{~s}$, $\left.3 \mathrm{H}, \mathrm{CH}_{3}\right), 2.50-2.66\left(\mathrm{~m}, 2 \mathrm{H}, \mathrm{CH}_{2}\right), 2.77-2.79\left(\mathrm{~m}, 2 \mathrm{H}, \mathrm{CH}_{2}\right), 6.27(\mathrm{~d}, 1 \mathrm{H}$, furan proton), 7.14-8.29 (m, 6H, olefinic $\mathrm{CH}$, furan proton, Ar-H), $9.25(\mathrm{~s}, 1 \mathrm{H}, \mathrm{NH}$, $\mathrm{D}_{2} \mathrm{O}$ exchangeable $) ;{ }^{13} \mathrm{C}$ NMR $\left(\mathrm{CDCl}_{3}\right): \delta 13.37,20.57,24.10,28.40,109.98$, 116.07, 123.33, 124.93, 125.72, 127.36, 129.07, 130.66, 136.56, 139.12, 147.01, 152.65, 156.05, 159.11; MS, m/z (\%): $319\left[\mathrm{M}^{+}\right](13), 318\left[\mathrm{M}^{+}-1\right](13), 160$ 
[C $\mathrm{C}_{10} \mathrm{H}_{12} \mathrm{~N}_{2}$ ] (100); Anal. For $\mathrm{C}_{19} \mathrm{H}_{17} \mathrm{~N}_{3} \mathrm{O}_{2}$ (319.36): Calcd. (\%) C, 71.46; H, 5.37; N, 13.16; Found(\%): C, 71.57; H, 5.12; N, 13.53.

2-Cyano-N'- (2,3-dihydronaphthalen-4 (1H)-ylidene)-3- (3,4,5-trimethoxyphenyl) acrylohydrazide $(3 \mathrm{c})$

Yield $61 \%$, yellow powder (from ethanol), mp. $285-286^{\circ} \mathrm{C}$; IR $\left(\mathrm{KBr}, \mathrm{cm}^{-1}\right)$ : $3334(\mathrm{NH}), 3051$ (CH arom.), 2938, 2857 (CH aliph.), 2217 (CN), 1667 (C=O), $1586(\mathrm{C}=\mathrm{N}) ;{ }^{1} \mathrm{H}$ NMR $\left(\mathrm{DMSO}_{-} \mathrm{d}_{6}\right): \delta 1.95-1.99\left(\mathrm{~m}, 2 \mathrm{H}, \mathrm{CH}_{2}\right), 2.58-2.61(\mathrm{~m}, 2 \mathrm{H}$, $\left.\mathrm{CH}_{2}\right), 2.73-2.77\left(\mathrm{~m}, 2 \mathrm{H}, \mathrm{CH}_{2}\right), 3.62,3.74\left(2 \mathrm{~s}, 9 \mathrm{H}, 3\left(\mathrm{OCH}_{3}\right)\right), 6.63-8.23(\mathrm{~m}, 7 \mathrm{H}$, olefinic $\mathrm{CH}, \mathrm{Ar}-\mathrm{H}), 9.66$ (s, 1H, NH, $\mathrm{D}_{2} \mathrm{O}$ exchangeable); $\mathrm{MS}, \mathrm{m} / \mathrm{z}(\%): 405\left[\mathrm{M}^{+}\right]$ (3), $160\left[\mathrm{C}_{10} \mathrm{H}_{12} \mathrm{~N}_{2}\right]$ (35), $128\left[\mathrm{C}_{10} \mathrm{H}_{8}\right]$ (100); Anal. For $\mathrm{C}_{23} \mathrm{H}_{23} \mathrm{~N}_{3} \mathrm{O}_{4}$ (405.45): Calcd. (\%)C, 68.13; H, 5.72; N, 10.36; Found(\%): C, 68.32; H, 5.46; N, 10.49.

2-Cyano- $N^{\prime}-\quad$ (2,3-dihydronaphthalen-4 (1H)-ylidene)-3- $\quad$ (1H-indol-3-yl) acrylohydrazide (3d)

Yield $87 \%$, yellow powder (from methanol), mp. $270-271^{\circ} \mathrm{C}$; IR $\left(\mathrm{KBr}, \mathrm{cm}^{-1}\right)$ : 3368, 3158 (2NH), 3053 (CH arom.), 2941, 2846 (CH aliph.), 2201 (CN), 1675 $(\mathrm{C}=\mathrm{O}), 1576(\mathrm{C}=\mathrm{N}) ;{ }^{1} \mathrm{H}$ NMR (DMSO-d $\left.\mathrm{d}_{6}\right): \delta 1.83-1.87\left(\mathrm{~m}, 2 \mathrm{H}, \mathrm{CH}_{2}\right), 2.46-2.49$ (m, $\left.2 \mathrm{H}, \mathrm{CH}_{2}\right), 2.74-2.76\left(\mathrm{~m}, 2 \mathrm{H}, \mathrm{CH}_{2}\right), 7.19-8.57$ ( $\mathrm{m}, 10 \mathrm{H}$, olefinic $\left.\mathrm{CH}, \mathrm{Ar}-\mathrm{H}\right)$, $10.84,12.46\left(2 \mathrm{~s}, 2 \mathrm{H}, 2 \mathrm{NH}, \mathrm{D}_{2} \mathrm{O}\right.$ exchangeable); ${ }^{13} \mathrm{C}$ NMR (DMSO-d $\mathrm{d}_{6}$ ): $\delta 20.23$, $24.20,28.33,109.45,112.21,117.85,121.18,122.84,124.45,125.67,126.24$, 128.02, 128.80, 130.28, 131.70, 135.46, 139.61, 146.23, , 155.32, 159.21; MS, m/z (\%): $354\left[\mathrm{M}^{+}\right](15), 353\left[\mathrm{M}^{+}-1\right](21), 195\left[\mathrm{C}_{12} \mathrm{H}_{7} \mathrm{~N}_{2} \mathrm{O}\right]$ (100); Anal. For $\mathrm{C}_{22} \mathrm{H}_{18} \mathrm{~N}_{4} \mathrm{O}$ (354.40): Calcd. (\%) C, 74.56; H, 5.12; N, 15.81; Found(\%): C, 74.25; H, 5.38; N, 15.59 .

General procedure for the synthesis of 1-(2,3-Dihydronaphthalen-4(1H)ylideneamino) -6-amino-4- (substituted)-1,2-dihydro-2- oxopyridine-3,5dicarbonitrile $(4 a, b)$ and ethyl 1- (2,3-dihydronaphthalen-4(1H)-ylideneamino)2-amino-5-cyano-4-(substituted)-1,6-dihydro-6-oxopyridine-3-carboxylate (5a,b)

To a solution of compounds $3 \mathrm{a}, \mathrm{b}(0.01 \mathrm{~mol})$ in 1,4-dioxane $(30 \mathrm{ml})$ containing triethylamine $(1.0 \mathrm{ml})$ either malononitrile $(0.66 \mathrm{~g}, 0.01 \mathrm{~mol})$ or ethyl cyanoacetate $(1.13 \mathrm{~g}, 0.01 \mathrm{~mol})$ was added. The reaction mixture was heated under reflux for $3 \mathrm{hr}$ and then poured onto ice/cold water. The formed precipitate was filtered, dried and recrystallized from the proper solvent to give the title compounds $4 \mathrm{a}, \mathrm{b}$ and $5 \mathrm{a}, \mathrm{b}$, respectively.

1-(2,3-Dihydronaphthalen-4(1H)-ylideneamino)-6-amino-4-(4-fluorophenyl)1,2-dihydro-2-oxopyridine-3,5-dicarbonitrile (4a)

Yield 51\%, pale yellow powder (from benzene/pet. ether), mp. $143-144^{\circ} \mathrm{C}$; IR ( $\left.\mathrm{KBr}, \mathrm{cm}^{-1}\right): 3313,3199\left(\mathrm{NH}_{2}\right), 3058$ (CH arom.), 2939, 2841 (CH aliph.), 2212 $(\mathrm{CN}), 1675(\mathrm{C}=\mathrm{O}), 1610(\mathrm{C}=\mathrm{N}) ;{ }^{1} \mathrm{H}$ NMR (DMSO-d $\left.{ }_{6}\right)$ : $81.94-1.98\left(\mathrm{~m}, 2 \mathrm{H}, \mathrm{CH}_{2}\right)$, 2.76-2.79 (m, 2H, $\mathrm{CH}_{2}$ ), 2.92-2.98 (m, 2H, $\left.\mathrm{CH}_{2}\right), 7.19-8.30$ (m, 8H, Ar-H), 8.95 (s, $2 \mathrm{H}, \mathrm{NH}_{2}, \mathrm{D}_{2} \mathrm{O}$ exchangeable); $\mathrm{MS}, \mathrm{m} / \mathrm{z}(\%): 397\left[\mathrm{M}^{+}\right](23), 396\left[\mathrm{M}^{+}-1\right]$ (24), $369\left[\mathrm{M}^{+}-\mathrm{CO}\right]$ (27), $267\left[\mathrm{M}^{+}-\mathrm{C}_{10} \mathrm{H}_{10}\right]$ (16), $116\left[\mathrm{C}_{9} \mathrm{H}_{8}\right]$ (100); Anal. For 
$\mathrm{C}_{23} \mathrm{H}_{16} \mathrm{FN}_{5} \mathrm{O}$ (397.40): Calcd. C, 69.51; H, 4.06; N, 17.62; Found: C, 69.72; H, 4.25; N, 17.48 .

1-(2,3-Dihydronaphthalen-4(1H) -ylideneamino) -6-amino-1,2-dihydro-4-(5methylfuran- 2-yl) -2-oxopyridine-3,5-dicarbonitrile (4b)

Yield $57 \%$, brown powder (from benzene/pet. ether), mp. $128-129^{\circ} \mathrm{C}$; IR $\left(\mathrm{KBr}, \mathrm{cm}^{-1}\right): 3339,3212\left(\mathrm{NH}_{2}\right), 3050$ (CH arom.), 2935, 2840 (CH aliph.), 2205 $(\mathrm{CN}), 1661(\mathrm{C}=\mathrm{O}), 1624(\mathrm{C}=\mathrm{N}) ;{ }^{1} \mathrm{H} \mathrm{NMR}\left(\mathrm{CDCl}_{3}\right): \delta 1.96-2.05\left(\mathrm{~m}, 2 \mathrm{H}, \mathrm{CH}_{2}\right)$, $2.45\left(\mathrm{~s}, 3 \mathrm{H}, \mathrm{CH}_{3}\right), 2.54-2.60\left(\mathrm{~m}, 2 \mathrm{H}, \mathrm{CH}_{2}\right), 2.72-2.79\left(\mathrm{~m}, 2 \mathrm{H}, \mathrm{CH}_{2}\right), 6.27,6.70$ (2d, $2 \mathrm{H}$, furan protons), 7.16-8.00 (m, 4H, Ar-H), $9.23\left(\mathrm{~s}, 2 \mathrm{H}, \mathrm{NH}_{2}, \mathrm{D}_{2} \mathrm{O}\right.$ exchangeable); MS, m/z (\%): $383\left[\mathrm{M}^{+}\right](58), 384\left[\mathrm{M}^{+}+1\right](41), 357\left[\mathrm{M}^{+}-\mathrm{CN}\right]$ (43), $251\left[\mathrm{M}^{+}-\mathrm{C}_{10} \mathrm{H}_{12}\right]$ (43), $115\left[\mathrm{C}_{9} \mathrm{H}_{7}\right]$ (100); Anal. For $\mathrm{C}_{22} \mathrm{H}_{17} \mathrm{~N}_{5} \mathrm{O}_{2}$ (383.40): Calcd. (\%) C, 68.92; H, 4.47; N, 18.27; Found(\%): C, 68.75; H, 4.60; N, 17.91.

Ethyl 1-(2,3-dihydronaphthalen-4(1H)-ylideneamino) -2-amino-5-cyano-4(4-fluorophenyl) -1,6-dihydro-6-oxopyridine-3-carboxylate (5a)

Yield 58\%, brown powder (from benzene/pet. ether), mp. $108-109^{\circ} \mathrm{C}$; IR $\left(\mathrm{KBr}, \mathrm{cm}^{-1}\right)$ : 3435, 3314 ( $\left.\mathrm{NH}_{2}\right), 3052$ (CH arom.), 2934, 2860 (CH aliph.), 2213 $(\mathrm{CN}), 1735(\mathrm{C}=\mathrm{O}$, ester $), 1642(\mathrm{C}=\mathrm{O}), 1595(\mathrm{C}=\mathrm{N}) ;{ }^{1} \mathrm{H}$ NMR $\left(\mathrm{CDCl}_{3}\right): \delta 1.29(\mathrm{t}$, $\left.3 \mathrm{H},-\mathrm{CO}_{2} \mathrm{CH}_{2} \mathrm{CH}_{3}\right), 1.91-1.96\left(\mathrm{~m}, 2 \mathrm{H}, \mathrm{CH}_{2}\right), 2.59-2.63\left(\mathrm{~m}, 2 \mathrm{H}, \mathrm{CH}_{2}\right), 2.71-2.76$ (m, 2H, $\mathrm{CH}_{2}$ ), 4.33 (q, 2H, $\left.-\mathrm{CO}_{2} \underline{\mathrm{CH}}_{2} \mathrm{CH}_{3}\right), 7.02-8.12$ (m, 8H, Ar-H), 9.45 (s, 2H, $\mathrm{NH}_{2}, \mathrm{D}_{2} \mathrm{O}$ exchangeable); MS, m/z (\%): $444\left[\mathrm{M}^{+}\right](9), 443\left[\mathrm{M}^{+}-1\right](6), 416\left[\mathrm{M}^{+}-\right.$ $\left.\mathrm{C}_{2} \mathrm{H}_{4}\right]$ (30), $371\left[\mathrm{M}^{+}-\mathrm{C}_{3} \mathrm{H}_{5} \mathrm{O}_{2}\right](10), 115\left[\mathrm{C}_{9} \mathrm{H}_{7}\right]$ (100); Anal. For $\mathrm{C}_{25} \mathrm{H}_{21} \mathrm{FN}_{4} \mathrm{O}_{3}$ (444.46): Calcd. (\%)C, 67.56; H, 4.76; N, 12.61; Found(\%): C, 67.29; H, 4.43; N, 12.85 .

Ethyl 1-(2,3-dihydronaphthalen-4 (1H)-ylideneamino) -2-amino -5-cyano 1,6-dihydro-4-(5-methylfuran-2-yl)-6-oxopyridine-3-carboxylate (5b)

Yield 55\%, brown powder (from benzene/pet. ether), mp. $117-118^{\circ} \mathrm{C}$; IR ( $\left.\mathrm{KBr}, \mathrm{cm}^{-1}\right): 3411,3342$ ( $\left.\mathrm{NH}_{2}\right), 3064$ (CH arom.), 2930, 2869 (CH aliph.), 2208 $(\mathrm{CN}), 1745\left(\mathrm{C}=\mathrm{O}\right.$, ester), $1651(\mathrm{C}=\mathrm{O}), 1610(\mathrm{C}=\mathrm{N}) ;{ }^{1} \mathrm{H} \mathrm{NMR}\left(\mathrm{CDCl}_{3}\right): \delta 1.36(\mathrm{t}$, $\left.3 \mathrm{H},-\mathrm{CO}_{2} \mathrm{CH}_{2} \mathrm{CH}_{3}\right), 1.93-1.95\left(\mathrm{~m}, 2 \mathrm{H}, \mathrm{CH}_{2}\right), 2.44\left(\mathrm{~s}, 3 \mathrm{H}, \mathrm{CH}_{3}\right), 2.61-2.65(\mathrm{~m}, 2 \mathrm{H}$, $\left.\mathrm{CH}_{2}\right), 2.73-2.77\left(\mathrm{~m}, 2 \mathrm{H}, \mathrm{CH}_{2}\right), 4.31\left(\mathrm{q}, 2 \mathrm{H},-\mathrm{CO}_{2} \underline{\mathrm{CH}}_{2} \mathrm{CH}_{3}\right), 6.11,6.70(2 \mathrm{~d}, 2 \mathrm{H}$, furan protons), 7.16-8.00 (m, $4 \mathrm{H}, \mathrm{Ar}-\mathrm{H}), 9.17\left(\mathrm{~s}, 2 \mathrm{H}, \mathrm{NH}_{2}, \mathrm{D}_{2} \mathrm{O}\right.$ exchangeable); MS, m/z (\%): $430\left[\mathrm{M}^{+}\right]$(31), $431\left[\mathrm{M}^{+}+1\right](34), 416\left[\mathrm{M}^{+}-\mathrm{CH}_{2}\right]$ (28), $356\left[\mathrm{M}^{+}-\right.$ $\left.\mathrm{C}_{3} \mathrm{H}_{6} \mathrm{O}_{2}\right]$ (33), $55\left[\mathrm{C}_{4} \mathrm{H}_{7}\right]$ (100); Anal. For $\mathrm{C}_{24} \mathrm{H}_{22} \mathrm{~N}_{4} \mathrm{O}_{4}$ (430.46): Calcd. (\%)C, 66.97; H, 5.15; N, 13.02; Found(\%): C, 66.75; H, 5.31; N, 12.79.

General procedure for the synthesis of 5-Amino-3-(substituted)-N'-(2,3dihydronaphthalen-4(1H)-ylidene)-1H-pyrazole-4-carbohydrazide (6a,c,d)

A mixture of compounds $3 \mathrm{a}, \mathrm{c}, \mathrm{d}(0.002 \mathrm{~mol})$ and hydrazine hydrate $(0.2 \mathrm{ml}$, $0.004 \mathrm{~mol}, 99 \%)$ in absolute ethanol $(15 \mathrm{ml})$ was refluxed for $3 \mathrm{hr}$. After cooling, the formed precipitate was filtered, dried and recrystallized from the proper solvent to give the title compounds $6 \mathrm{a}, \mathrm{c}, \mathrm{d}$. 
5-Amino-3-(4-fluorophenyl)- $N$ '- (2,3-dihydronaphthalen-4 (1H)-ylidene)- $1 H$ pyrazole -4-carbohydrazide (6a)

Yield $61 \%$, pale brown powder (from methanol), mp. $254-255^{\circ} \mathrm{C}$; IR ( $\mathrm{KBr}$, $\mathrm{cm}^{-1}$ ): 3430, $3314\left(\mathrm{NH}_{2}, 2 \mathrm{NH}\right), 3055$ (CH arom.), 2919, 2850 (CH aliph.), 1632 $(\mathrm{C}=\mathrm{O}), 1587(\mathrm{C}=\mathrm{N})$; ${ }^{1} \mathrm{H}$ NMR $\left(\mathrm{DMSO}_{-} \mathrm{d}_{6}\right): \delta 1.85-1.89\left(\mathrm{~m}, 2 \mathrm{H}, \mathrm{CH}_{2}\right), 2.66-2.68$ (m, 2H, $\mathrm{CH}_{2}$ ), 2.70-2.76 (m, 2H, $\mathrm{CH}_{2}$ ), 7.21-7.60 (m, 8H, Ar-H), 8.14, 8.16, 8.53 $\left(3 \mathrm{~s}, 4 \mathrm{H}, \mathrm{NH}_{2}, 2 \mathrm{NH}, \mathrm{D}_{2} \mathrm{O}\right.$ exchangeable); $\mathrm{MS}, \mathrm{m} / \mathrm{z}(\%): 363\left[\mathrm{M}^{+}\right](60), 364$ $\left[\mathrm{M}^{+}+1\right](62), 362\left[\mathrm{M}^{+}-1\right](57), 267\left[\mathrm{C}_{14} \mathrm{H}_{13} \mathrm{~N}_{5} \mathrm{O}\right](74), 139\left[\mathrm{C}_{4} \mathrm{H}_{5} \mathrm{~N}_{5} \mathrm{O}\right](100) ;$ Anal. For $\mathrm{C}_{20} \mathrm{H}_{18} \mathrm{FN}_{5} \mathrm{O}$ (363.39): Calcd. (\%)C, 66.10; H, 4.99; N, 19.27; Found(\%): C, 66.36; H, 5.22; N, 19.38 .

5-Amino-N'-(2,3-dihydronaphthalen-4 (1H)-ylidene)-3- (3,4,5-trimethoxyphenyl)1H-pyrazole -4- carbohydrazide (6c)

Yield 68\%, yellow powder (from methanol), $\mathrm{mp}>300 ; \mathrm{IR}\left(\mathrm{KBr}, \mathrm{cm}^{-1}\right): 3271$, 3191, 3108 ( $\left.\mathrm{NH}_{2}, 2 \mathrm{NH}\right), 3052$ (CH arom.), 2938, 2840 (CH aliph.), 1642 (C=O), $1588(\mathrm{C}=\mathrm{N}) ;{ }^{1} \mathrm{H}$ NMR (DMSO-d $\left.{ }_{6}\right): \delta 1.81-1.86\left(\mathrm{~m}, 2 \mathrm{H}, \mathrm{CH}_{2}\right), 2.62-2.66(\mathrm{~m}, 2 \mathrm{H}$, $\left.\mathrm{CH}_{2}\right), 2.71-2.75\left(\mathrm{~m}, 2 \mathrm{H}, \mathrm{CH}_{2}\right), 3.71,3.77\left(2 \mathrm{~s}, 9 \mathrm{H}, 3\left(\mathrm{OCH}_{3}\right)\right), 7.11-7.71(\mathrm{~m}, 6 \mathrm{H}$, Ar-H), 8.20, 8.33, 8.64 (3s, 4H, $\mathrm{NH}_{2}, 2 \mathrm{NH}, \mathrm{D}_{2} \mathrm{O}$ exchangeable); $\mathrm{MS}, \mathrm{m} / \mathrm{z}(\%)$ : $435\left[\mathrm{M}^{+}\right]$(76), $436\left[\mathrm{M}^{+}+1\right](58), 250\left[\mathrm{C}_{12} \mathrm{H}_{16} \mathrm{~N}_{3} \mathrm{O}_{3}\right](60), 189\left[\mathrm{C}_{11} \mathrm{H}_{13} \mathrm{~N}_{2} \mathrm{O}\right](66)$, $52\left[\mathrm{C}_{4} \mathrm{H}_{4}\right]$ (100); Anal. For $\mathrm{C}_{23} \mathrm{H}_{25} \mathrm{~N}_{5} \mathrm{O}_{4}$ (435.48): Calcd. (\%)C, 63.44; H, 5.79; N, 16.08; Found(\%): C, 63.72; H, 5.61; N, 16.35 .

5-Amino-N'- (2,3-dihydronaphthalen -4(1H)-ylidene)-3-(1H-indol-3-yl) - $1 \mathrm{H}$ pyrazole -4- carbohydrazide (6d)

Yield $68 \%$, pale yellow powder (from ethanol), mp. $227-228^{\circ} \mathrm{C}$; IR $\left(\mathrm{KBr}, \mathrm{cm}^{-1}\right)$ : broad band centered at 3215, $3111\left(\mathrm{NH}_{2}, 3 \mathrm{NH}\right), 3056$ ( $\mathrm{CH}$ arom.), 2931, $2872(\mathrm{CH}$ aliph.), $1651(\mathrm{C}=\mathrm{O}), 1582(\mathrm{C}=\mathrm{N}) ;{ }^{1} \mathrm{H}$ NMR (DMSO-d $\left.{ }_{6}\right): \delta 1.82-1.89(\mathrm{~m}, 2 \mathrm{H}$, $\mathrm{CH}_{2}$ ), 2.64-2.68 (m, 2H, $\left.\mathrm{CH}_{2}\right), 2.79-2.81\left(\mathrm{~m}, 2 \mathrm{H}, \mathrm{CH}_{2}\right), 7.19-7.91(\mathrm{~m}, 9 \mathrm{H}, \mathrm{Ar}-\mathrm{H})$, 8.34, 8.76, 8.90, $11.75\left(4 \mathrm{~s}, 5 \mathrm{H}, \mathrm{NH}_{2}, 3 \mathrm{NH}, \mathrm{D}_{2} \mathrm{O}\right.$ exchangeable); $\mathrm{MS}, \mathrm{m} / \mathrm{z}(\%)$ : $384\left[\mathrm{M}^{+}\right](45), 385\left[\mathrm{M}^{+}+1\right](35), 255\left[\mathrm{C}_{12} \mathrm{H}_{11} \mathrm{~N}_{6} \mathrm{O}\right](43), 80\left[\mathrm{C}_{6} \mathrm{H}_{8}\right]$ (100), 116 $\left[\mathrm{C}_{8} \mathrm{H}_{6} \mathrm{~N}\right]$ (77); Anal. For $\mathrm{C}_{22} \mathrm{H}_{20} \mathrm{~N}_{6} \mathrm{O}$ (384.43): Calcd. (\%)C, 68.73; H, 5.24; N, 21.86; Found: (\%) C, 68.50; H, 5.43; N, 21.61.

General procedure for the synthesis of 2-Cyano- $N$ '-(2,3-dihydronaphthalen4(1H)-ylidene)-2-(4-methyl-3-(substituted)thiazol-2(3H)-ylidene)acetohydrazide $(8 a, b)$

To a stirred suspension of finely powdered potassium hydroxide $(0.56 \mathrm{~g}, 0.01$ $\mathrm{mol})$ in dry dimethylformamide $(20 \mathrm{ml})$, cyanoacetohydrazide $1(2.27 \mathrm{~g}, 0.01$ mol) was added with continuous stirring for $30 \mathrm{~min}$. Then either phenylisothiocyanate or $p$-methoxy phenylisothiocyanate $(0.01 \mathrm{~mol})$ was added slowly over the course of $10 \mathrm{~min}$. After complete addition, stirring of the reaction mixture was continued at room temperature overnight. Then chloroacetone $(0.85$ $\mathrm{ml}, 0.01 \mathrm{~mol}$ ) was added to the reaction mixture and stirred for $24 \mathrm{hr}$. The reaction mixture was poured onto ice/cold water containing few drops of hydrochloric acid. The formed precipitate was filtrated, dried, and recrystallized from the proper solvent to give the title compounds $8 \mathrm{a}, \mathrm{b}$.

Egypt. J. Chem. 57, No.4 (2014) 
2-Cyano-N'- (2,3-dihydronaphthalen -4(1H)-ylidene) -2-(4-methyl-3-phenylthiazol2(3H)-ylidene) acetohydrazide (8a)

Yield $68 \%$, reddish brown powder (from ethanol), mp. $131-132^{\circ} \mathrm{C}$; IR $(\mathrm{KBr}$, $\mathrm{cm}^{-1}$ ): 3408 (NH), 3042 (CH arom.), 2938, 2850 (CH aliph.), $2184(\mathrm{CN}), 1657$ $(\mathrm{C}=\mathrm{O}), 1572(\mathrm{C}=\mathrm{N}) ;{ }^{1} \mathrm{H}$ NMR $\left(\mathrm{CDCl}_{3}\right): \delta 1.70-1.88\left(\mathrm{~m}, 2 \mathrm{H}, \mathrm{CH}_{2}\right), 2.16(\mathrm{~s}, 3 \mathrm{H}$, $\left.\mathrm{CH}_{3}\right), 2.64-2.67\left(\mathrm{~m}, 2 \mathrm{H}, \mathrm{CH}_{2}\right), 2.70-2.76\left(\mathrm{~m}, 2 \mathrm{H}, \mathrm{CH}_{2}\right), 6.95-8.27(\mathrm{~m}, 10 \mathrm{H}, \mathrm{CH}-$ thiazole proton and $\mathrm{Ar}-\mathrm{H}), 11.56\left(\mathrm{~s}, 1 \mathrm{H}, \mathrm{NH}, \mathrm{D}_{2} \mathrm{O}\right.$ exchangeable); ${ }^{13} \mathrm{C}$ NMR $\left(\mathrm{CDCl}_{3}\right): \delta 20.49,21.08,26.59,28.65,100.28,119.09,120.02,123.8,125.02$, $125.88,128.19,128.23,128.60,128.93,130.11,140.02,143.21,147.21,152.11$, 159.01, 163.22; MS, m/z (\%): $400\left[\mathrm{M}^{+}\right](5), 399\left[\mathrm{M}^{+}-1\right](5), 258\left[\mathrm{C}_{13} \mathrm{H}_{12} \mathrm{~N}_{3} \mathrm{OS}\right]$ (18), $160\left[\mathrm{C}_{10} \mathrm{H}_{12} \mathrm{~N}_{2}\right]$ (28), $84\left[\mathrm{C}_{3} \mathrm{H}_{2} \mathrm{NS}\right]$ (100); Anal. For $\mathrm{C}_{23} \mathrm{H}_{20} \mathrm{~N}_{4} \mathrm{OS}$ (400.50): Calcd. (\%)C, 68.98; H, 5.03; N, 13.99; S, 8.01; Found(\%): C, 68.71; H, 5.26; N, $13.75 ; \mathrm{S}, 7.82$

2-Cyano-N'-(2,3-dihydronaphthalen-4(1H)-ylidene)-2-(3-(4-methoxyphenyl)4-methylthiazol-2(3H)-ylidene)acetohydrazide (8b)

Yield 79\%, brown powder (from ethanol), mp. 144-145 ${ }^{\circ} \mathrm{C}$; IR $\left(\mathrm{KBr}, \mathrm{cm}^{-1}\right)$ : 3409 (NH), 3052 (CH arom.), 2932, 2841 ( $\mathrm{CH}$ aliph.), $2182(\mathrm{CN}), 1650(\mathrm{C}=\mathrm{O})$, $1570(\mathrm{C}=\mathrm{N}) ;{ }^{1} \mathrm{H}$ NMR $\left(\mathrm{CDCl}_{3}\right): \delta 1.90-1.97\left(\mathrm{~m}, 2 \mathrm{H}, \mathrm{CH}_{2}\right), 2.15\left(\mathrm{~s}, 3 \mathrm{H}, \mathrm{CH}_{3}\right)$, 2.65-2.67 (m, 2H, $\mathrm{CH}_{2}$ ), 2.70-2.77 (m, 2H, $\mathrm{CH}_{2}$ ), 3.82 (s, 3H, $\left.\mathrm{OCH}_{3}\right), 6.91-8.29$ (m, 9H, CH-thiazole proton and $\mathrm{Ar}-\mathrm{H}), 11.54$ (s, 1H, NH, $\mathrm{D}_{2} \mathrm{O}$ exchangeable); MS, m/z (\%): $430\left[\mathrm{M}^{+}\right]$(25), $159\left[\mathrm{C}_{10} \mathrm{H}_{11} \mathrm{~N}_{2}\right]$ (75), $77\left[\mathrm{C}_{6} \mathrm{H}_{5}\right]$ (100); Anal. For $\mathrm{C}_{24} \mathrm{H}_{22} \mathrm{~N}_{4} \mathrm{O}_{2} \mathrm{~S}$ (430.52): Calcd. (\%)C, 66.96; H, 5.15; N, 13.01; S, 7.45; Found(\%): C, 67.21; H, 5.31; N, 12.83; S, 7.19.

2-Cyano- $N^{\prime}-\quad$ (2,3-dihydronaphthalen -4(1H)-ylidene) -2-(3,4-(disubstituted) thiazol-2 (3H) -ylidene) acetohydrazide $(9 a, b)$

To a stirred suspension of finely powdered potassium hydroxide $(0.56 \mathrm{~g}, 0.01$ mol) in dry dimethylformamide $(20 \mathrm{ml})$, cyanoacetohydrazide $1(2.27 \mathrm{~g}, 0.01$ mol) was added and continuous stirring was done for $30 \mathrm{~min}$. Then either phenylisothiocyanate or $p$-methoxy phenylisothiocyanate $(0.01 \mathrm{~mol})$ was added slowly over the course of $10 \mathrm{~min}$. After complete addition, stirring of the reaction mixture was continued at room temperature overnight. Then either phenacyl bromide or $p$-bromophenacyl bromide $(0.01 \mathrm{~mol})$ was added to the reaction mixture and stirred for the $12 \mathrm{hr}$. The reaction mixture was poured onto ice/cold water containing few drops of hydrochloric acid. The formed precipitate was filtrated, dried and recrystallized from the proper solvent to give the title compounds $9 \mathrm{a}, \mathrm{b}$.

2-Cyano-N'-(2,3-dihydronaphthalen-4 (1H)-ylidene)-2- (3,4-diphenylthiazol2(3H)-ylidene) acetohydrazide (9a)

Yield 55\%, reddish brown powder (from methanol), mp. $112-113^{\circ} \mathrm{C}$; IR (KBr, $\mathrm{cm}^{-1}$ ): $3394(\mathrm{NH}), 3062$ (CH arom.), 2935, 2839 (CH aliph.), $2179(\mathrm{CN}), 1642$ $(\mathrm{C}=\mathrm{O}), 1576(\mathrm{C}=\mathrm{N}) ;{ }^{1} \mathrm{H}$ NMR $\left(\mathrm{CDCl}_{3}\right): \delta 1.95-1.99\left(\mathrm{~m}, 2 \mathrm{H}, \mathrm{CH}_{2}\right), 2.67-2.75(\mathrm{~m}$, $\left.2 \mathrm{H}, \mathrm{CH}_{2}\right), 2.80-2.86\left(\mathrm{~m}, 2 \mathrm{H}, \mathrm{CH}_{2}\right), 6.95-8.10(\mathrm{~m}, 15 \mathrm{H}, \mathrm{CH}-$ thiazole proton and Ar-H), 11.55 (s, 1H, NH, $\mathrm{D}_{2} \mathrm{O}$ exchangeable); ${ }^{13} \mathrm{C} \mathrm{NMR}\left(\mathrm{CDCl}_{3}\right): \delta 20.38,26.01$, 
28.61, 101.78, 119.08, 123.53, 126.29, 126.72, 127.54, 127.90, 128.11, 128.85, 128.92, 129.59, 138.91, 140.21, 140.81, 150.10, 157.11, 161.37; MS, m/z (\%): $462\left[\mathrm{M}^{+}\right]$(10), $160\left[\mathrm{C}_{10} \mathrm{H}_{12} \mathrm{~N}_{2}\right]$ (75), $77\left[\mathrm{C}_{6} \mathrm{H}_{5}\right]$ (100); Anal. For $\mathrm{C}_{28} \mathrm{H}_{22} \mathrm{~N}_{4} \mathrm{OS}$ (462.57): Calcd. (\%) C, 72.70; H, 4.79; N, 12.11; S, 6.93; Found(\%): C, 72.55; H, 4.60; N, 12.35; S, 6.71 .

2-(4-(4-Bromophenyl)-3-(4-methoxyphenyl) thiazol-2(3H)-ylidene)-2-cyano$N^{\prime}-(2,3-$ dihydronaphthalen-4(1H)-ylidene) acetohydrazide (9b)

Yield $84 \%$, yellowish brown powder (from ethanol), mp. $118-119^{\circ} \mathrm{C}$; IR $\left(\mathrm{KBr}, \mathrm{cm}^{-1}\right): 3394(\mathrm{NH}), 3062$ (CH arom.), 2935, 2839 (CH aliph.), $2171(\mathrm{CN})$, $1642(\mathrm{C}=\mathrm{O}), 1576(\mathrm{C}=\mathrm{N})$; ${ }^{1} \mathrm{H}$ NMR $\left(\mathrm{DMSO}_{6}\right): \delta 2.00-2.04\left(\mathrm{~m}, 2 \mathrm{H}, \mathrm{CH}_{2}\right), 2.80-$ $2.83\left(\mathrm{~m}, 2 \mathrm{H}, \mathrm{CH}_{2}\right), 2.91-2.95\left(\mathrm{~m}, 2 \mathrm{H}, \mathrm{CH}_{2}\right), 3.80\left(\mathrm{~s}, 3 \mathrm{H}, \mathrm{OCH}_{3}\right), 6.87(\mathrm{~s}, 1 \mathrm{H}, \mathrm{CH}-$ thiazole proton $), 7.18-8.01(\mathrm{~m}, 12 \mathrm{H}, \mathrm{Ar}-\mathrm{H}), 11.52\left(\mathrm{~s}, 1 \mathrm{H}, \mathrm{NH}, \mathrm{D}_{2} \mathrm{O}\right.$ exchangeable); MS, m/z (\%): 571, $573\left[\mathrm{M}^{+}+1\right](3,5), 183,185\left[\mathrm{C}_{7} \mathrm{H}_{6} \mathrm{BrN}\right](100$, 85); Anal. For $\mathrm{C}_{29} \mathrm{H}_{23} \mathrm{BrN}_{4} \mathrm{O}_{2} \mathrm{~S}$ (571.49): Calcd. (\%)C, 60.95; H, 4.06; N, 9.80; S, 5.61; Found(\%): C, 61.24; H, 4.31; N, 9.63; S, 5.86.

General procedure for the synthesis of 2-cyano- $N^{\prime}-(2,3$-dihydronaphthalen4(1H)-ylidene) -2-(4-oxo-3- (substituted)thiazolidin-2-ylidene) acetohydrazide $(10 a, b)$

To a stirred suspension of finely powdered potassium hydroxide $(0.56 \mathrm{~g}, 0.01$ mol) in dry dimethylformamide $(20 \mathrm{ml})$, cyanoacetohydrazide $1(2.27 \mathrm{~g}, 0.01$ mol) was added and continuous stirring was done for $30 \mathrm{~min}$. Then either phenylisothiocyanate or $p$-methoxy phenylisothiocyanate $(0.01 \mathrm{~mol})$ was added slowly over the course of $10 \mathrm{~min}$. After complete addition, stirring of the reaction mixture was continued at room temperature overnight. Then ethyl bromoacetate $(1.67 \mathrm{ml}, 0.01 \mathrm{~mol})$ was added to the reaction mixture and stirred for the $24 \mathrm{hr}$. The reaction mixture was poured onto ice/cold water containing few drops of hydrochloric acid. The formed precipitate was filtrated, dried and recrystallized from the proper solvent to give title compounds $10 \mathrm{a}, \mathrm{b}$.

2-Cyano-N'- (2,3-dihydronaphthalen-4 (1H)-ylidene) -2-(4-oxo-3-phenylthiazolidin -2-ylidene) acetohydrazide (10a)

Yield $89 \%$, green powder (from ethanol), mp. $195-196^{\circ} \mathrm{C}$; IR $\left(\mathrm{KBr}, \mathrm{cm}^{-1}\right)$ : 3378 (NH), 3052 (CH arom.), 2936, 2849 (CH aliph.), $2186(\mathrm{CN}), 1741(\mathrm{C}=\mathrm{O})$, $1672(\mathrm{C}=\mathrm{O}), 1590(\mathrm{C}=\mathrm{N}) ;{ }^{1} \mathrm{H}$ NMR $\left(\mathrm{CDCl}_{3}\right): \delta 1.80-1.87\left(\mathrm{~m}, 2 \mathrm{H}, \mathrm{CH}_{2}\right), 2.65-$ $2.71\left(\mathrm{~m}, 2 \mathrm{H}, \mathrm{CH}_{2}\right), 2.85-2.92\left(\mathrm{~m}, 2 \mathrm{H}, \mathrm{CH}_{2}\right), 3.85\left(\mathrm{~s}, 2 \mathrm{H}, \mathrm{CH}_{2}\right.$-thiazolidinon protons), 7.07-8.25 (m, 9H, Ar- $\mathrm{H}), 9.09\left(\mathrm{~s}, 1 \mathrm{H}, \mathrm{NH}, \mathrm{D}_{2} \mathrm{O}\right.$ exchangeable); ${ }^{13} \mathrm{C}$ NMR $\left(\mathrm{CDCl}_{3}\right): \delta 20.50,23.91,28.35,31.09,35.57,112.77,124.71,125.70$, $127.37,128.25,128.91,129.13,130.51,133.02$, 139.03, 151.56, 159.10, 161.64, 168.82, 171.55; MS, m/z (\%): $399\left[\mathrm{M}^{-3}\right](54), 328\left[\mathrm{C}_{20} \mathrm{H}_{16} \mathrm{~N}_{4} \mathrm{O}\right](68), 162$ $\left[\mathrm{C}_{10} \mathrm{H}_{14} \mathrm{~N}_{2}\right]$ (90), $73\left[\mathrm{C}_{5} \mathrm{H}_{13}\right]$ (100); Anal. For $\mathrm{C}_{22} \mathrm{H}_{18} \mathrm{~N}_{4} \mathrm{O}_{2} \mathrm{~S}$ (402.47): Calcd. (\%)C, 65.65; H, 4.51; N, 13.92; S, 7.97; Found(\%): C, 65.34; H, 4.82; N, 13.71; S, 7.68 .

Egypt. J. Chem. 57, No.4 (2014) 
2-Cyano-N'-(2,3-dihydronaphthalen-4(1H)-ylidene)-2-(3-(4-methoxyphenyl)4-oxothiazolidin-2-ylidene)acetohydrazide (10b)

Yield $94 \%$, brown powder (from ethanol), mp. $201-202^{\circ} \mathrm{C}$; IR $\left(\mathrm{KBr}, \mathrm{cm}^{-1}\right)$ : $3373(\mathrm{NH}), 3064$ (CH arom.), 2936, 2842 (CH aliph.), $2191(\mathrm{CN}), 1739(\mathrm{C}=\mathrm{O})$, $1668(\mathrm{C}=\mathrm{O}), 1582(\mathrm{C}=\mathrm{N}){ }^{1} \mathrm{H}$ NMR $\left(\mathrm{DMSO}-\mathrm{d}_{6}\right): \delta 1.77-1.79\left(\mathrm{~m}, 2 \mathrm{H}, \mathrm{CH}_{2}\right), 2.07-$ $2.10\left(\mathrm{~m}, 2 \mathrm{H}, \mathrm{CH}_{2}\right), 2.68-2.71\left(\mathrm{~m}, 2 \mathrm{H}, \mathrm{CH}_{2}\right), 3.80\left(\mathrm{~s}, 3 \mathrm{H}, \mathrm{OCH}_{3}\right), 3.98(\mathrm{~s}, 2 \mathrm{H}$, $\mathrm{CH}_{2}$-thiazole protons), 7.12-8.29 (m, $\left.8 \mathrm{H}, \mathrm{Ar}-\mathrm{H}\right), 8.96\left(\mathrm{~s}, 1 \mathrm{H}, \mathrm{NH}, \mathrm{D}_{2} \mathrm{O}\right.$ exchangeable); MS, m/z (\%): $431\left[\mathrm{M}^{-1}\right](63), 430\left[\mathrm{M}^{-2}\right](53), 378\left[\mathrm{C}_{20} \mathrm{H}_{18} \mathrm{~N}_{4} \mathrm{O}_{2} \mathrm{~S}\right]$ (90), $188\left[\mathrm{C}_{11} \mathrm{H}_{12} \mathrm{~N}_{2} \mathrm{O}\right]$ (66), $159\left[\mathrm{C}_{10} \mathrm{H}_{11} \mathrm{~N}_{2}\right]$ (100); Anal. For $\mathrm{C}_{23} \mathrm{H}_{20} \mathrm{~N}_{4} \mathrm{O}_{3} \mathrm{~S}$ (432.49): Calcd. (\%) C, 63.87; H, 4.66; N, 12.95; S, 7.41; Found(\%): C, 64.13; H, 4.43; N, 12.67; S, 7.58.

2-Cyano- $N^{\prime}-\quad$ (2,3-dihydronaphthalen $\quad$-4(1H)-ylidene) $\quad$-2-(3-(substituted)-5((substituted) hydrazinylidene) -4-oxothiazolidin-2-ylidene) acetohydrazide (11a,b)

To a cold solution of compounds $10 \mathrm{a}, \mathrm{b}(0.005 \mathrm{~mol})$ in ethanol $(20 \mathrm{ml})$ containing sodium acetate $(1.5 \mathrm{~g})$, the appropriate substituted benzenediazonium salt $(0.005 \mathrm{~mol})$ [prepared by adding sodium nitrite $(0.8 \mathrm{~g}, 0.01 \mathrm{~mol})$ in water $(8$ $\mathrm{ml}$ ) to a cold solution of the appropriate substitute aniline either $p$-toluidine or $p$ bromoaniline in the appropriate amount of hydrochloric acid] was added with continuous stirring for $6 \mathrm{hr}$. The formed precipitate was filtered, washed several times with water, dried and recrystallized from the proper solvent to give the title compounds 11a,b.

2-Cyano- $N$ '-(2,3-dihydronaphthalen-4 (1H)-ylidene)-2- $\quad$ (3-(phenyl)-5-((4methylphenyl) hydrazinylidene) -4-oxothiazolidin-2-ylidene) acetohydrazide (11a)

Yield 51\%, reddish brown powder (from dioxane), mp. $209-210^{\circ} \mathrm{C}$; IR $(\mathrm{KBr}$, $\left.\mathrm{cm}^{-1}\right)$ : 3436, 3322 (2NH), 3061 (CH arom.), 2934, 2846 (CH aliph.), $2193(\mathrm{CN})$, $1740(\mathrm{C}=\mathrm{O}), 1670(\mathrm{C}=\mathrm{O}), 1590(\mathrm{C}=\mathrm{N}) ;{ }^{1} \mathrm{H}$ NMR $\left(\mathrm{CDCl}_{3}\right): \delta 1.89-1.91(\mathrm{~m}, 2 \mathrm{H}$, $\left.\mathrm{CH}_{2}\right), 2.46$ (s, $\left.3 \mathrm{H}, \mathrm{CH}_{3}\right), 2.68-2.70\left(\mathrm{~m}, 2 \mathrm{H}, \mathrm{CH}_{2}\right), 2.72-2.75\left(\mathrm{~m}, 2 \mathrm{H}, \mathrm{CH}_{2}\right), 7.24-$ $8.25(\mathrm{~m}, 13 \mathrm{H}, \mathrm{Ar}-\mathrm{H}), 9.09,12.75\left(2 \mathrm{~s}, 2 \mathrm{H}, 2 \mathrm{NH}, \mathrm{D}_{2} \mathrm{O}\right.$ exchangeable $) ; \mathrm{MS}, \mathrm{m} / \mathrm{z}$ (\%): $520\left[\mathrm{M}^{+1}\right](23), 519\left[\mathrm{M}^{+}\right]$(33), $504\left[\mathrm{M}-\mathrm{CH}_{3}\right]$ (28), $57\left[\mathrm{C}_{4} \mathrm{H}_{9}\right]$ (100); Anal. For $\mathrm{C}_{29} \mathrm{H}_{24} \mathrm{~N}_{6} \mathrm{O}_{2} \mathrm{~S}(520.60)$ : Calcd. $(\%) \mathrm{C}, 66.90 ; \mathrm{H}, 4.65 ; \mathrm{N}, 16.14 ; \mathrm{S}, 6.16$; Found(\%): C, 66.53; H, 4.50; N, 16.31; S, 6.34.

2-Cyano- $N^{\prime}-(2,3-d i h y d r o n a p h t h a l e n-4(1 H)-y l i d e n e)-2-(3-(4-m e t h o x y p h e n y l)-$ 5-((4-bromophenyl)hydrazinylidene)-4-oxothiazolidin-2-ylidene) acetohydrazide (11b)

Yield 55\%, dark yellow powder (from dioxane), mp. 194-195 ${ }^{\circ}$; IR ( $\mathrm{KBr}$, $\left.\mathrm{cm}^{-1}\right)$ : 3448, 3350 (2NH), 3051 (CH arom.), 2936, 2848 (CH aliph.), $2193(\mathrm{CN})$, $1735(\mathrm{C}=\mathrm{O}), 1664(\mathrm{C}=\mathrm{O}), 1585(\mathrm{C}=\mathrm{N}) ;{ }^{1} \mathrm{H}$ NMR $\left(\mathrm{CDCl}_{3}\right): \delta 1.89-2.04(\mathrm{~m}, 2 \mathrm{H}$, $\left.\mathrm{CH}_{2}\right), 2.40-2.47\left(\mathrm{~m}, 2 \mathrm{H}, \mathrm{CH}_{2}\right), 2.71-2.86\left(\mathrm{~m}, 2 \mathrm{H}, \mathrm{CH}_{2}\right), 3.68\left(\mathrm{~s}, 3 \mathrm{H}, \mathrm{OCH}_{3}\right)$, 7.10-8.24 (m, 12H, Ar-H), 8.54, 9.14, $\left(2 \mathrm{~s}, 2 \mathrm{H}, 2 \mathrm{NH}, \mathrm{D}_{2} \mathrm{O}\right.$ exchangeable $) ;{ }^{13} \mathrm{C}$ NMR $\left(\mathrm{CDCl}_{3}\right): \delta 20.43,23.50,28.10,54.63,114.25,115.63,122.05,122.16$, 124.06, 125.63, 127.44, 129.07, 129.33, 130.49, 131.11, 139.35, 159.10, 161.28, 167.21, 171.41; MS, m/z (\%): 616, $614\left[\mathrm{M}^{+}\right](48,35), 535\left[\mathrm{M}^{+}-\mathrm{Br}\right](25), 189$ $\left[\mathrm{C}_{11} \mathrm{H}_{13} \mathrm{~N}_{2} \mathrm{O}\right] \quad$ (28), $160 \quad\left[\mathrm{C}_{10} \mathrm{H}_{12} \mathrm{~N}_{2}\right] \quad$ (28), $69 \quad\left[\mathrm{C}_{5} \mathrm{H}_{9}\right] \quad(100)$; Anal. For 
$\mathrm{C}_{29} \mathrm{H}_{23} \mathrm{BrN}_{6} \mathrm{O}_{3} \mathrm{~S}$ (615.50): Calcd. (\%) C, 56.59; H, 3.77; N, 13.65; S, 5.21; Found(\%): C, 56.68; H, 3.51; N, 13.45; S, 5.40.

General procedure for the synthesis of 2-cyano-N'-(2,3-dihydronaphthalen4(1H)-ylidene)-3,3-dimercaptoacrylohydrazide (13)

To a stirred suspension of finely powdered potassium hydroxide $(1.12 \mathrm{~g}, 0.02$ mol) in dry dimethylformamide $(20 \mathrm{ml})$ cyanoacetohydrazide $1(2.27 \mathrm{~g}, 0.01$ mol) was added. The resulted mixture was cooled at $10^{\circ} \mathrm{C}$ in an ice bath and then carbon disulfide $(0.80 \mathrm{ml}, 0.01 \mathrm{~mol})$ was added slowly over the course of $10 \mathrm{~min}$. After complete addition, stirring of the reaction mixture was continued for overnight. Then hydrochloric acid $(2 \mathrm{M}, 5 \mathrm{ml})$ was added dropwisely and stirring was continued for additional $2 \mathrm{hr}$. The reaction mixture was poured onto ice/cold water. The formed precipitate was filtrated, dried, and recrystallized from the proper solvent to give the title compound 13.

Yield $89 \%$, yellowish brown powder (from ethanol), mp. $112-113^{\circ} \mathrm{C}$; IR $\left(\mathrm{KBr}, \mathrm{cm}^{-1}\right)$ : 3390, (NH), 3048 (CH arom.), 2933, 2841 (CH aliph.), $2188(\mathrm{CN})$, $1671(\mathrm{C}=\mathrm{O}), 1590(\mathrm{C}=\mathrm{N}) ;{ }^{1} \mathrm{H}$ NMR $\left(\mathrm{CDCl}_{3}\right): \delta 1.87-2.00\left(\mathrm{~m}, 2 \mathrm{H}, \mathrm{CH}_{2}\right), 2.65-$ $2.71\left(\mathrm{~m}, 2 \mathrm{H}, \mathrm{CH}_{2}\right), 2.86-2.90\left(\mathrm{~m}, 2 \mathrm{H}, \mathrm{CH}_{2}\right), 7.20-8.20(\mathrm{~m}, 4 \mathrm{H}, \mathrm{Ar}-\mathrm{H}), 10.30$, $10.72,10.81\left(3 \mathrm{~s}, 3 \mathrm{H}, \mathrm{NH}, 2 \mathrm{SH}, \mathrm{D}_{2} \mathrm{O}\right.$ exchangeable $) ;{ }^{13} \mathrm{C} \mathrm{NMR}\left(\mathrm{CDCl}_{3}\right): \delta 20.70$, 22.24, 28.24, 112.93, 124.13, 125.69, 127.91, 128.74, 131.44, 132.87, 139.60, 144.11, 151.13, 159.93; MS, m/z (\%): $304\left[\mathrm{M}^{+}+1\right]$ (39), $303\left[\mathrm{M}^{+}\right]$(40), 118 $\left[\mathrm{C}_{9} \mathrm{H}_{10}\right]$ (100); Anal. For $\mathrm{C}_{14} \mathrm{H}_{13} \mathrm{~N}_{3} \mathrm{OS}_{2}$ (303.40): Calcd. (\%) C, 55.42; H, 4.32; N, 13.85; S, 21.14; Found(\%): C, 55.63; H, 4.51; N, 13.57; S, 21.27.

General procedure for the synthesis of ethyl 2-(2-(2,3-dihydronaphthalen-4(1H)ylideneaminocarbamoyl)-2-cyano-1-mercaptovinylthio)acetate (14)

To a stirred suspension of finely powdered potassium hydroxide (1.12 g, 0.02 mol) in dry dimethylformamide $(20 \mathrm{ml})$ cyanoacetohydrazides $1(2.27 \mathrm{~g}, 0.01$ mol) was added. The resulted mixture was cooled at $10^{\circ} \mathrm{C}$ in an ice bath and then carbon disulfide $(0.80 \mathrm{ml}, 0.01 \mathrm{~mol})$ was added slowly over the course of $10 \mathrm{~min}$. After complete addition, stirring of the reaction mixture was continued overnight. Then ethyl bromoacetate $(1.2 \mathrm{ml}, 0.01 \mathrm{~mol})$ was added to the mixture and stirring continued for $3 \mathrm{hr}$, then the mixture was poured onto ice/cold water and acidified by hydrochloric acid. The formed precipitate was filtrated, dried, and recrystallized from the proper solvent to give title compound 14.

Yield 82\%, brown powder (from ethanol), mp. 196-197 ${ }^{\circ} \mathrm{C}$; IR $\left(\mathrm{KBr}, \mathrm{cm}^{-1}\right)$ : 3421, (NH), 3056 (CH arom.), 2934, 2833 (CH aliph.), 2175 (CN), 1730 (C=O, ester), $1655(\mathrm{C}=\mathrm{O}), 1578(\mathrm{C}=\mathrm{N}) ;{ }^{1} \mathrm{H} \mathrm{NMR}\left(\mathrm{CDCl}_{3}\right): \delta 1.18\left(\mathrm{t}, 3 \mathrm{H},-\mathrm{CO}_{2} \mathrm{CH}_{2} \underline{\mathrm{CH}}_{3}\right)$ 1.83-1.87 (m, 2H, $\left.\mathrm{CH}_{2}\right), 2.69-2.73\left(\mathrm{~m}, 2 \mathrm{H}, \mathrm{CH}_{2}\right), 2.85-2.89\left(\mathrm{~m}, 2 \mathrm{H}, \mathrm{CH}_{2}\right), 3.48$ (s, $\left.2 \mathrm{H},-\mathrm{CH}_{2}-\right), 4.03$ (q, $\left.2 \mathrm{H},-\mathrm{CO}_{2} \mathrm{CH}_{2} \mathrm{CH}_{3}\right), 7.17-8.04$ (m, 4H, Ar-H), 13.20 (s, $1 \mathrm{H}, \mathrm{NH}, \mathrm{D}_{2} \mathrm{O}$ exchangeable); ${ }^{13} \mathrm{C}$ NMR (DMSO-d 6 ): $\delta 13.49,20.80,27.11$, $28.28,34.95,60.19,94.25,94.44,124.04,125.60,127.76,127.99,132.07$, 138.98, 147.29, 161.72, 168.52, 188.19; MS, m/z (\%): $389\left[\mathrm{M}^{+}\right](28), 388\left[\mathrm{M}^{+}-1\right]$ (27), $363\left[\mathrm{M}^{+}-\mathrm{CN}\right]$ (24), $356\left[\mathrm{M}^{+}-\mathrm{SH}\right]$ (23), $73\left[\mathrm{C}_{5} \mathrm{H}_{13}\right]$ (100); Anal. For

Egypt. J. Chem. 57, No.4 (2014) 
$\mathrm{C}_{18} \mathrm{H}_{19} \mathrm{~N}_{3} \mathrm{O}_{3} \mathrm{~S}_{2}$ (389.49): Calcd. (\%)C, 55.51; H, 4.92; N, 10.79; S, 16.47; Found(\%): C, 55.84; H, 5.09; N, 10.93; S, 16.73 .

2-Cyano- $N$ - (2,3-dihydronaphthalen-4 (1H)-ylidene) -3,3-bis (methylthio) acrylohydrazide (15)

To a stirred suspension of finely powdered potassium hydroxide $(1.12 \mathrm{~g}, 0.02$ $\mathrm{mol})$ in dry DMF (20 ml) cyanoacetohydrazides 1 (2.27 g, $0.01 \mathrm{~mol})$ was added. The resulted mixture was cooled at $10^{\circ} \mathrm{C}$ in an ice bath and then carbon disulfide $(0.80 \mathrm{ml}, 0.01 \mathrm{~mol})$ was added slowly over the course of $10 \mathrm{~min}$. After complete addition, stirring of the reaction mixture was continued overnight. Then dimethyl sulfate $(1.14 \mathrm{ml}, 0.012 \mathrm{~mol})$ was added to the mixture and stirring continued overnight, then the mixture was poured onto ice/cold water. The formed precipitate was filtrated, dried and recrystallized from the proper solvent to give the title compound 15 .

Yield 56\%, yellowish brown powder (from ethanol), mp. $228-229^{\circ} \mathrm{C}$; IR $\left(\mathrm{KBr}, \mathrm{cm}^{-1}\right): 3190(\mathrm{NH}), 3056$ (CH arom.), 2931, 2840 (CH aliph.), $2192(\mathrm{CN})$, $1664(\mathrm{C}=\mathrm{O}), 1592(\mathrm{C}=\mathrm{N}) ;{ }^{1} \mathrm{H}$ NMR $\left(\mathrm{DMSO}_{6}\right): \delta 1.85-1.89\left(\mathrm{~m}, 2 \mathrm{H}, \mathrm{CH}_{2}\right), 2.48$ (s, 6H, 2- $\left.\mathrm{SCH}_{3}\right), 2.61-2.65\left(\mathrm{~m}, 2 \mathrm{H}, \mathrm{CH}_{2}\right), 2.86-2.93\left(\mathrm{~m}, 2 \mathrm{H}, \mathrm{CH}_{2}\right), 7.19-8.10$ (m, $4 \mathrm{H}, \mathrm{Ar}-\mathrm{H}), 10.30\left(\mathrm{~s}, 1 \mathrm{H}, \mathrm{NH}, \mathrm{D}_{2} \mathrm{O}\right.$ exchangeable); ${ }^{13} \mathrm{C} \mathrm{NMR}\left(\mathrm{DMSO}-\mathrm{d}_{6}\right): \delta$ $20.20,21.74,26.40,27.75,112.46,123.62,125.17,127.88,128.21,130.94$, $132.39,139.08,143.58,150.61,159.43,183.1 ; \mathrm{MS}, \mathrm{m} / \mathrm{z}(\%): 332\left[\mathrm{M}^{+1}\right](23), 331$ $\left[\mathrm{M}^{+}\right]$(34), $315\left[\mathrm{M}^{+}-\mathrm{CH}_{4}\right]$ (23), $84\left[\mathrm{C}_{6} \mathrm{H}_{12}\right](100)$; Anal. For $\mathrm{C}_{16} \mathrm{H}_{17} \mathrm{~N}_{3} \mathrm{OS}_{2}$ (331.46): Calcd. (\%) C, 57.98; H, 5.17; N, 12.68; S, 19.35; Found(\%): C, 57.63; H, 5.26; N, 12.45; S, 19.64.

General procedure for the synthesis of 5-Amino-N'-(2,3-dihydronaphthalen4(1H)-ylidene)-3- (methylthio)-1-(substituted) -1H-pyrazole -4-carbohydrazide $(16 a, b)$

A mixture of compound $15(0.67 \mathrm{~g}, 0.002 \mathrm{~mol})$ and hydrazine hydrate or phenylhydrazine $(0.003 \mathrm{~mol})$ in ethanol $(15 \mathrm{ml})$ was heated under reflux for $3 \mathrm{hr}$. After cooling the formed precipitate was filtrated, dried, and recrystallized from the proper solvent to give the title compound 16a,b.

5-Amino-N'-(2,3-dihydronaphthalen-4(1H)-ylidene)-3-(methylthio)-1H-pyrazole 4-carbohydrazide (16a)

Yield 52\%, pale brown powder (from ethanol), mp. $247-248^{\circ} \mathrm{C}$; IR (KBr, cm $\left.{ }^{1}\right)$ : 3430, $3192\left(2 \mathrm{NH}, \mathrm{NH}_{2}\right), 3054$ (CH arom.), 2970, 2852 (CH aliph.), 1667 $(\mathrm{C}=\mathrm{O}), 1593(\mathrm{C}=\mathrm{N}) ;{ }^{1} \mathrm{H}$ NMR $\left(\mathrm{DMSO}_{\mathrm{d}}\right): \delta 1.88-1.90\left(\mathrm{~m}, 2 \mathrm{H}, \mathrm{CH}_{2}\right), 2.47(\mathrm{~s}$, $\left.3 \mathrm{H},-\mathrm{SCH}_{3}\right), 2.63-2.67\left(\mathrm{~m}, 2 \mathrm{H}, \mathrm{CH}_{2}\right), 2.72-2.76\left(\mathrm{~m}, 2 \mathrm{H}, \mathrm{CH}_{2}\right), 7.20-8.04(\mathrm{~m}, 4 \mathrm{H}$, Ar-H), 10.50, 12.72, 12.92 (s, 4H, 2NH, $\mathrm{NH}_{2}, \mathrm{D}_{2} \mathrm{O}$ exchangeable); $\mathrm{MS}, \mathrm{m} / \mathrm{z}(\%)$ : $316\left[\mathrm{M}^{+}+1\right](12), 315\left[\mathrm{M}^{+}\right](11), 159\left[\mathrm{C}_{10} \mathrm{H}_{11} \mathrm{~N}_{2}\right](11), 69\left[\mathrm{C}_{5} \mathrm{H}_{9}\right]$ (100); Anal. For $\mathrm{C}_{15} \mathrm{H}_{17} \mathrm{~N}_{5} \mathrm{OS}$ (315.39): Calcd. (\%) C, 57.12; H, 5.43; N, 22.21; S, 10.17; Found(\%): C, 56.86; H, 5.71; N, 22.53; S, 10.35. 
5-Amino-N'-(2,3-dihydronaphthalen-4(1H)-ylidene)-3-(methylthio)-1-phenyl1H-pyrazole-4-carbohydrazide (16b)

Yield $61 \%$, yellowish brown powder (from ethanol), mp. $245-246^{\circ} \mathrm{C}$; IR $\left(\mathrm{KBr}, \mathrm{cm}^{-1}\right): 3427,3192\left(2 \mathrm{NH}, \mathrm{NH}_{2}\right), 3051$ (CH arom.), 2969, 2931, $2842(\mathrm{CH}$ aliph.), $1651(\mathrm{C}=\mathrm{O}), 1595(\mathrm{C}=\mathrm{N}) ;{ }^{1} \mathrm{H}$ NMR (DMSO-d $\left.\mathrm{d}_{6}\right): \delta 1.86-1.89(\mathrm{~m}, 2 \mathrm{H}$, $\mathrm{CH}_{2}$ ), $2.48\left(\mathrm{~s}, 3 \mathrm{H},-\mathrm{SCH}_{3}\right), 2.63-2.67\left(\mathrm{~m}, 2 \mathrm{H}, \mathrm{CH}_{2}\right), 2.71-2.76\left(\mathrm{~m}, 2 \mathrm{H}, \mathrm{CH}_{2}\right)$, 7.21-8.07 (m, 9H, Ar-H), 10.30, 12.73 (2s, 3H, NH, $\mathrm{NH}_{2}, \mathrm{D}_{2} \mathrm{O}$ exchangeable); MS, m/z (\%): $392\left[\mathrm{M}^{+1}\right](57), 391\left[\mathrm{M}^{+}\right](80), 390\left[\mathrm{M}^{-1}\right](63), 339\left[\mathrm{M}^{+}-\mathrm{C}_{4} \mathrm{H}_{4}\right]$ (100); Anal. For $\mathrm{C}_{21} \mathrm{H}_{21} \mathrm{~N}_{5} \mathrm{OS}$ (391.49): Calcd. (\%)C, 64.43; H, 5.41; N, 17.89; S, 8.19; Found(\%): C, 64.72; H, 5.13; N, 17.61; S, 8.38.

3-Amino-4,5,6,7- tetrahydro- $N^{\prime}$ - (2,3- dihydronaphthalen-4 (1H)-ylidene) benzo [b]thiophene-2- carbohydrazide (17)

A mixture of cyanoacetohydrazides $1(0.70 \mathrm{~g}, 0.003 \mathrm{~mol})$, cyclohexanone $(0.30 \mathrm{ml}, 0.003 \mathrm{~mol})$ and elemental sulfur $(0.10 \mathrm{~g}, 0.003 \mathrm{~mol})$ in dioxane $(20 \mathrm{ml})$ containing triethylamine $(1 \mathrm{ml})$ was refluxed for $5 \mathrm{hr}$. The reaction mixture was poured onto ice/cold water. The formed precipitate was filtrated, dried, and recrystallized from the proper solvent to give title compound 17.

Yield $56 \%$, dark brown powder (from dioxane), mp137-138 $\mathrm{C}$; IR $\left(\mathrm{KBr}, \mathrm{cm}^{-1}\right)$ : broad band centered at $3422\left(\mathrm{NH}, \mathrm{NH}_{2}\right), 3059(\mathrm{CH}$ arom.), 2930, $2863(\mathrm{CH}$ aliph.), $1663(\mathrm{C}=\mathrm{O}), 1582(\mathrm{C}=\mathrm{N}) ;{ }^{1} \mathrm{H}$ NMR (DMSO-d $\left.)_{6}\right): \delta 1.66-1.91(\mathrm{~m}, 6 \mathrm{H}$, $\left.3 \mathrm{CH}_{2}\right), 2.63-2.98\left(\mathrm{~m}, 8 \mathrm{H}, 4 \mathrm{CH}_{2}\right), 7.08-8.03(\mathrm{~m}, 4 \mathrm{H}, \mathrm{Ar}-\mathrm{H}), 9.02,10.21(\mathrm{~s}, 3 \mathrm{H}$, $\mathrm{NH}, \mathrm{NH}_{2}, \mathrm{D}_{2} \mathrm{O}$ exchangeable); $\mathrm{MS}, \mathrm{m} / \mathrm{z}(\%): 340\left[\mathrm{M}^{+1}\right](38), 339\left[\mathrm{M}^{+}\right](47), 194$ $\left[\mathrm{C}_{9} \mathrm{H}_{10} \mathrm{~N}_{2} \mathrm{OS}\right]$ (46), $64\left[\mathrm{C}_{5} \mathrm{H}_{4}\right]$ (100); Anal. For $\mathrm{C}_{19} \mathrm{H}_{21} \mathrm{~N}_{3} \mathrm{OS}$ (339.45): Calcd. (\%) C, 67.23; H, 6.24; N, 12.38; S, 9.45; Found: (\%) C, 67.54; H, 6.53; N, 12.61; S, 9.73.

4-Amino-2,3-dihydro-N'-(2,3-dihydronaphthalen-4(1H)-ylidene)-3- phenyl-2thioxothiazole-5-carbohydrazide (18)

A mixture of cyanoacetohydrazides $1(0.70 \mathrm{~g}, 0.003 \mathrm{~mol})$, phenylisothiocynate $(0.36 \mathrm{~g}, 0.003 \mathrm{~mol})$ and elemental sulfur $(0.10 \mathrm{~g}, 0.003 \mathrm{~mol})$ in dioxane $(20 \mathrm{ml})$ containing triethylamine $(1 \mathrm{ml})$ was refluxed for $6 \mathrm{hr}$. After cooling the formed precipitate was filtrated, dried, and recrystallized from the proper solvent to give title compound 18 .

Yield 70\%, dark brown powder (from ethanol), mp. 242-243 ${ }^{\circ} \mathrm{C}$; IR $\left(\mathrm{KBr}, \mathrm{cm}^{-1}\right)$ : 3441, 3284, $3168\left(\mathrm{NH}, \mathrm{NH}_{2}\right.$ ), 3052 (CH arom.), 2927, 2866 (CH aliph.), 1680 $(\mathrm{C}=\mathrm{O}), 1582(\mathrm{C}=\mathrm{N}), 1250(\mathrm{C}=\mathrm{S}) ;{ }^{1} \mathrm{H}$ NMR $\left(\mathrm{DMSO}_{-}\right): \delta 1.78-1.82(\mathrm{~m}, 2 \mathrm{H}$, $\mathrm{CH}_{2}$ ), 2.67-2.69 (m, 2H, $\left.\mathrm{CH}_{2}\right)$, 2.74-2.87 (m, 2H, $\left.\mathrm{CH}_{2}\right)$, 7.24-8.15 (m, 9H, Ar$\mathrm{H}), 10.48$ (s, 1H, NH, D $2 \mathrm{O}$ exchangeable); MS, m/z (\%): $395\left[\mathrm{M}^{+1}\right]$ (32), 394 $\left[\mathrm{M}^{+}\right]$(100), $235\left[\mathrm{C}_{10} \mathrm{H}_{7} \mathrm{~N}_{2} \mathrm{OS}_{2}\right]$ (67), $208\left[\mathrm{C}_{9} \mathrm{H}_{8} \mathrm{~N}_{2} \mathrm{~S}_{2}\right]$ (56), $160\left[\mathrm{C}_{10} \mathrm{H}_{12} \mathrm{~N}_{2}\right]$ (34); Anal. For $\mathrm{C}_{20} \mathrm{H}_{18} \mathrm{~N}_{4} \mathrm{OS}_{2}$ (394.51): Calcd. (\%) C, 60.89; H, 4.60; N, 14.20; S, 16.26; Found(\%): C, 60.65; H, 4.36; N, 14.47; S, 16.38.

Egypt. J. Chem. 57, No.4 (2014) 


\section{Biological Evaluation}

\section{Antimicrobial assay}

Most of the newly synthesized chemical compounds were individually tested against a panel of gram positive and gram negative bacterial pathogens, yeast and fungi. Antimicrobial tests were carried out by the agar well diffusion method ${ }^{(39)}$ using $100 \mu \mathrm{L}$ of suspension containing $1 \times 10^{8} \mathrm{CFU} / \mathrm{ml}$ of pathological tested bacteria, $1 \times 10^{6} \mathrm{CFU} / \mathrm{ml}$ of yeast and $1 \times 10^{6}$ of fungi spread on nutrient agar (NA), Sabourand dextrose agar (SDA) and potato dextrose agar (PDA), respectively. After the media had cooled and solidified, wells $(10 \mathrm{~mm}$ in diameter) were made in the solidified agar and loaded with $100 \mu \mathrm{L}$ of tested compound solution prepared by dissolving $200 \mathrm{mg}$ of the chemical compound in one $\mathrm{ml}$ of dimethyl sulfoxide (DMSO). The inculcated plates were then incubated for $24 \mathrm{hr}$ at $37^{\circ} \mathrm{C}$ for bacteria and $48 \mathrm{hr}$ at $28^{\circ} \mathrm{C}$ for yeast and fungi. Negative controls were prepared using DMSO employed for dissolving the tested compound. (Ciprofloxacin $(50 \mathrm{mg} / \mathrm{ml}$ and Clotrimazole $(50 \mathrm{mg} / \mathrm{ml})$ were used as standard for antibacterial and antifungal activity, respectively. After incubation time, antimicrobial activity was evaluated by measuring the zone of inhibition against the test organisms and compared with that of the standard. The observed zone of inhibition is presented in Table 1. Antimicrobial activities were expressed as inhibition diameter zones in millimeters $(\mathrm{mm})$. The experiment was carried out in triplicate and the average zone of inhibition was calculated.

Minimal inhibitory concentration (MIC) measurement

The antimicrobial activity of the active compounds (having inhibition zones $(I Z) \geq 16 \mathrm{~mm}$ ) was then evaluated using the two fold serial dilution technique ${ }^{(40)}$. Two fold serial dilutions of the tested compounds solutions were prepared using the proper nutrient broth. The final concentration of the solutions was 200, 100, $50,25 \mathrm{mg} / \mathrm{ml}$. Each $2 \mathrm{ml}$ received $0.1 \mathrm{ml}$ of the appropriate inoculums and incubated at $37^{\circ} \mathrm{C}$ for $24 \mathrm{hr}$ for bacteria and $48 \mathrm{hr}$ at $28^{\circ} \mathrm{C}$ for yeast and fungi, respectively. The lowest concentration showing no growth was taken as the minimum inhibitory concentration (MIC) (Table 2).

\section{Antiviral assay}

MTT cytotoxicity assay (TC50)

Samples were 10-fold serially diluted with Dulbecco's Modified Eagle's Medium (DMEM). Stock solutions of the test compounds were prepared in $10 \%$ DMSO in distilled $\mathrm{H}_{2} \mathrm{O}$. The cytotoxic activity of the extracts were tested in Madin Darby Canine kidney (MDCK) cells by using the 3-(4,5-dimethylthiazol2-yl)-2,5-diphenyltetrazolium bromide (MTT) method ${ }^{(41)}$ with minor modification. Briefly, the cells were seeded in 96 well-plates $(100 \mu \mathrm{l} /$ well at a density of $3 \times 10^{5}$ cells $/ \mathrm{ml}$ ) and incubated for $24 \mathrm{hr}$ at $37^{\circ} \mathrm{C}$ in $5 \% \mathrm{CO}_{2}$. After $24 \mathrm{hr}$, cells were treated with various concentrations of the tested compounds in triplicates. After further $24 \mathrm{hr}$, the supernatant was discarded and cell monolayers were washed with sterile phosphate buffer saline (PBS) 3 times and MTT 
solution ( $20 \mu \mathrm{L}$ of $5 \mathrm{mg} / \mathrm{ml}$ stock solution) was added to each well and incubated at $37^{\circ} \mathrm{C}$ for $4 \mathrm{hr}$ followed by medium aspiration. In each well, the formed formazan crystals were dissolved with $200 \mu \mathrm{L}$ of acidified isopropanol $(0.04 \mathrm{M}$ $\mathrm{HCl}$ in absolute isopropanol $=0.073 \mathrm{ml} \mathrm{HCl}$ in $50 \mathrm{ml}$ isopropanol). Absorbance of formazan solutions were measured at $\lambda \max 540 \mathrm{~nm}$ with $620 \mathrm{~nm}$ as a reference wavelength using a multi-well plate reader. The percentage of cytotoxicity compared to the untreated cells was determined with the following equation.

The plot of \% cytotoxicity versus sample concentration was used to calculate the concentration which exhibited $50 \%$ cytotoxicity $\left(\mathrm{LD}_{50}\right)$.

\section{Plaque reduction assay}

Assay was carried out according to the method of Hayden et al. ${ }^{(42)}$ in a six well plate where MDCK cells $\left(10^{5}\right.$ cells $\left./ \mathrm{ml}\right)$ were cultivated for $24 \mathrm{hr}$ at $37^{\circ} \mathrm{C}$. A/CHICKEN/QALUBIA/1/2006 (H5N1) virus was diluted to give $10^{4} \mathrm{PFU} /$ well and mixed with the safe concentration of the tested compounds, $1 \mu \mathrm{g} / \mathrm{ml}$ of L-1(tosyl-amido-2-phenyl) ethyl chloromethyl ketone (TCPK) and incubated for one hour at $37^{\circ} \mathrm{C}$ before being added to the cells. Growth medium was removed from the cell culture plates and virus-Cpd or virus-extract and Virus-Zanamivir mixtures were inoculated $(100 \mu \mathrm{l} /$ well $)$, After $1 \mathrm{hr}$ contact time for virus adsorption, $3 \mathrm{ml}$ of DMEM supplemented with $2 \%$ agarose was added onto the cell monolayer, plates were left to solidify and incubated at $37^{\circ} \mathrm{C}$ till formation of viral plaques ( 3 to 4 days). Formalin (10\%) was added for two hours then plates were stained with $0.1 \%$ crystal violet in distilled water. Control wells were included where untreated virus was incubated with MDCK cells and finally plaques were counted and percentage reduction in plaques formation in comparison to control wells was recorded as the following:

$\%$ inhibition $=$ viral count $($ untreated $)-$ viral count $($ treated $) /$ viral count $($ untreated $) \times 100$

\section{References}

1. Kotaiah, Y., Nagaraju, K., Harikrishna, N., Venkata Rao, C., Yamini, L. and Vijjulatha, M., Synthesis, docking and evaluation of antioxidant and antimicrobial activities of novel 1,2,4-triazolo[3,4-b][1,3,4]thiadiazol-6-yl)selenopheno[2,3d]pyrimidines. Eur. J. Med. Chem. 75, 195-202 (2014).

2. Apostolidis, I., Liaras, K., Geronikaki, A., Hadjipavlou-Litina, D., Gavalas, A., Sokovic, M., Glamoclija, J. and Ciric, A., Synthesis and biological evaluation of some 5-arylidene-2-(1,3-thiazol-2-ylimino)-1,3-thiazolidin-4-ones as dual antiinflammatory/antimicrobial agents. Bioorg. Med. Chem. 21, 532-539 (2013).

3. Thapa, M., Kim, Y., Desper, J., Kyeong-Ok, C. and Hua, D.H., Synthesis and antiviral activity of substituted quercetins. Bioorg. Med. Chem. Lett. 22, 353-256 (2012). 
4. Bekhita, A.A., Ashoura, H.M.A. and Guemeib, A.A., Novel pyrazole derivatives as potential promising anti-inflammatory antimicrobial agents. Arch. Pharm. Chem. Life Sci. 338,167-174 (2005).

5. Barker, M., Clackers, M., Copley, R., Demaine, D.A., Inglis, G.G.A., Johnston, M.J., Jones, H.T., Haas, M.V., House, D. and Loiseau, R., Dissociated nonsteroidal glucocorticoid receptor modulators; discovery of the agonist trigger in a tetrahydronaphthalene-benzoxazine Series. J. Med. Chem. 49, 4216-4231 (2006).

6. Al-Abdullah, E.S., Synthesis and anticancer activity of some novel tetralin-6-ylpyrazoline, 2-Thioxopyrimidine, 2-oxopyridine, 2-thioxo-pyridine and 2iminopyridine derivatives. Molecules, 16, 3410-3419, (2011).

7. Hamdy, N.A., Gamal-Eldeen, A.M., Abdel-Aziz, H.A. and Fakhr, I.M.I., Synthesis of some 1, 3-thiazole, 1, 3, 4-thiadiazole, pyrazolo [5, 1-c]-1, 2, 4-triazine and 1, 2, 4-triazolo [5, 1-c]-1, 2, 4-triazine derivatives based on the thiazolo [3, 2-a] benzimidazole moiety. Eur. J. Med. Chem. 45, 463-470 (2010).

8. WahYee, S. and Simons, C., Synthesis and CYP24 inhibitory activity of 2substituted-3,4-dihydro-2H-naphthalen-1-one (tetralone) derivatives. Bioorg. Med. Chem. Lett. 14, 5651-5714 (2004).

9. Ates-Alagoz, Z., Yildiz, S. and Buyukbingol, E., Antimicrobial activities of some tetrahydronaphthalene- benzimidazole derivatives. Chemotherapy, 53, 110-113 (2007)

10. Tang, H., Zhou, Y.J., Li, Y.W., Lv, J.G., Zheng, C.H., Chen, J. and Zhu, J., Design, synthesis and antifungal activities in vitro of novel tetralin compounds. Chin. Chem. Lett. 19, 264-268 (2008).

11. Therkelsen, F., Jorgensen, P.T., Nielsen, C. and Pedersen, E.B., New emivirine (MKC442) analogues containing tetrahydronaphthalene at C6 and their anti HIV activity. Monatsh. Chem. 138, 495-503 (2007).

12. Hamdy, N.A. and EL-Senousy, W.M., Synthesis and antiviral evaluation of some novel pyrazoles and pyrazolo[3,4-d]pyridazines bearing 5,6,7,8-tetrahydronaphthalene. Acta Pol. Pharm. - Drug Research, 70, 99-110 (2013).

13. Kavitha, C., Basappa, S., Nanjunda, S., Mantelingu, K., Doreswamy, S., Sridhar, M.A., Sprasad, J. and Rangappa, K., Synthesis of new bioactive venlafaxine analogs: Novel thiazolidin-4-ones as antimicrobials. Bioorg. Med. Chem. 14, 22902299 (2006).

14. Ottana, R., Maccari, R., Barreca, M., Rotondo, G., Rossi, A., Chiricosta, A., Paola, G., Sautebin, R., Cuzzocrea, L. and Vigorita, S., 5-Arylidene-2-imino-4thiazolidinones: Design and synthesis of novel anti-inflammatory agents. Bioorg. Med. Chem. 13, 4243-4252 (2006).

15. Jain, A.K., Vaidya, A., Ravichandran, V., Kashaw, S.K. and Agrawal, R.K., Recent developments and biological activities of thiazolidinone derivatives: A review. Bioorg. Med. Chem. 20, 3378-3395 (2012). 
16. Al-Omary, F.A.M., Hassan, G.S., El-Messery, S.M. and El-Subbagh, H.I., Substituted thiazoles V. Synthesis and antitumor activity of novel thiazolo[2,3$b]$ quinazoline and pyrido[4,3-d]thiazolo[3,2-a]pyrimidine analogues. Eur. J. Med. Chem. 47, 65-72 (2012).

17. Liu, X.H., Cui, P., Song, B.A., Bhadury, P.S., Zhu, H.L. and Wang, S.F., Synthesis, structure and antibacterial activity of novel 1-(5-substituted-3-substituted4,5-dihydropyrazol-1-yl)ethanone oxime ester derivatives. Bioorg. Med. Chem. 16, 4075-4082 (2008).

18. Magedov, I.V., Manpadi, M., Van slambrouck, S., Steelant, W.F.A., Rozhkova, E., Przhevalskii, N.M., Rogelj, S. and Kornienko, A., Discovery and investigation of antiproliferative and apoptosis-inducing properties of new heterocyclic podophyllotoxin analogues accessible by a one-step multicomponent synthesis. $J$. Med. Chem. 50, 5183-5192 (2007).

19. Prasad, Y.R., Rao, A.L., Prasoona, L., Murali, K. and Kumar, P.R., Synthesis and antidepressant activity of some 1,3,5-triphenyl-2-pyrazolines and 3-(2"-hydroxy naphthalen-1"-yl)-1,5-diphenyl-2-pyrazolines. Bioorg. Med. Chem. Lett. 15, 5030$5034(2005)$

20. Ozdemir, Z., Kandilici, H.B., Gumusel, B., Calis, U. and Bilgin, A.A., Synthesis and studies on antidepressant and anticonvulsant activities of some 3-(2-furyl)pyrazoline derivatives. Eur. J. Med. Chem. 42, 373-379 (2007).

21. Sener, A., Sener, M.K., Bildmci, I., Kasimogullari, R. and Akçamur, Y., Studies on the reactions of cyclic oxalyl compounds with hydrazines or hydrazones : Synthesis and reactions of 4-benzoyl-1-(3-nitrophenyl)-5-phenyl-1H-pyrazole-3carboxylic acid. J. Heterocyclic Chem. 39, 869-875 (2002).

22. Refat, H.M. and Fadda, A.A., Synthesis and antimicrobial activity of some novel hydrazide, benzochromenone, dihydropyridine, pyrrole, thiazole and thiophene derivatives. Eur. J. Med. Chem. 70, 419-436 (2013).

23. Fadda, A.A., Afsah, E.M. and Awad, R.S., Synthesis and antimicrobial activity of some new benzo and naphthonitrile derivatives. Eur. J. Med. Chem. 60, 421-430 (2013).

24. Ragavendran, J.V., Sriram, D., Patel, S.K., Reddy, I.V., Bharathwajan, N., Stables, J. and Yogeeswari, P., Design and synthesis of anticonvulsants from a combined phthalimide-GABA-anilide and hydrazone pharmacophore. Eur. J. Med. Chem. 42, 146-151 (2007).

25. Acharya, B.N., Saraswat, D. and Kaushik, M.P., Pharmacophore based discovery of potential antimalarial agent targeting haem detoxification pathway. Eur. J. Med. Chem. 43, 2840-2852 (2008).

26. Yong, X., Chuan-Dong, F., Jing, Z., Dong-Soo, S. and Jun-Ying, M., Synthesis and structure-activity relationships of novel 1-arylmethyl-3-aryl- $1 H$-pyrazole-5carbohydrazide hydrazone derivatives as potential agents against A549 lung cancer cells. Eur. J. Med. Chem. 43, 2347-2353 (2008).

Egypt. J. Chem. 57, No.4 (2014) 
27. Zeldin, R.K. and Petruschke, R.A., Pharmacological and therapeutic properties of ritonavir-boosted protease inhibitor therapy in HIV-infected patients. J. Antimicrob. Chemother. 53, 4-9 (2004).

28. Winston, A., Back, D., Fletcher, C., Robinson, L., Unsworth, J., Tolowinska, I., Schutz, M., Pozniak, A.L., Gazzard, B. and Boffito, M., Effect of omeprazole on the pharmacokinetics of saquinavir-500 $\mathrm{mg}$ formulation with ritonavir in healthy male and female volunteers. AIDS, 20, 1401-1406 (2006).

29. Yamada, M., Watanabe, T., Miyara, T., Baba, N., Saito, J., Takeuchi, Y. and Ohsawa, F., Crystal structure of cefditoren complexed with Streptococcus pneumoniae penicillin-binding protein $2 \mathrm{X}$ : structural basis for its high antimicrobial activity. Antimicrob. Agents. Chemother. 51, 3902-3907 (2007).

30. De Jongh, R., Hens, R., Basma, V., Mouton, J.W., Tulkens, P.M. and Carryn, S., Continuous versus intermittent infusion of temocillin, a directed spectrum penicillin for intensive care patients with nosocomial pneumonia: stability, compatibility, population pharmacokinetic studies and breakpoint selection. $J$. Antimicrob. Chemother. 61, 382-388 (2008).

31. Ha-Duong, N.T., Dijols, S., Marques-Soares , C., Minoletti, D., Dansette, P.M. and Mansuy, D., Synthesis of sulfaphenazole derivatives and their use as inhibitors and tools for comparing the active sites of human liver cytochromes P450 of the $2 \mathrm{C}$ subfamily. J. Med. Chem. 25, 3622-3631 (2001).

32. Borelli, C., Schaller, M., Niewerth, M., Nocker, K., Baasner, B., Berg, D.,Tiemann, R., Tietjen, K., Fugmann, B., Lang-Fugmann, S. and Korting, H.C., Modes of action of the new arylguanidine abafungin beyond interference with ergosterol biosynthesis and in vitro activity against medically important fungi. Chemotherapy, 54, 245-259 (2008).

33. Lang, C.C., Jamal, S.K., Mohamed, Z., Mustafa, M.R., Mustafa, A.M. and Lee, T.C., Evidence of an interaction between nifedipine and nafcillin in humans. $B r . J$. Clin. Pharmacol. 55, 588-590 (2003).

34. Prasada Rao, K.V.V., Dandala, R., Handaa, V.K., Subramnyeswara Rao, I.V., Rani, A. and Naidub, A., Synthesis of process related compounds of Nafcillin sodium. ARKIVOC, xv 61-67 (2006).

35. Kotha, S. and Krishna, N.G., Synthetic approach to linearly annulated tetralin-based constrained $\alpha$-amino acid derivatives via Rongalite. Curr. Sci. 101, 923-926 (2011).

36. Singh, H., Sindhu, J., Khurana, J.M., Sharma, C. and Aneja, K.R., Ultrasound promoted one pot synthesis of novel fluorescent triazolyl spirocyclic oxindoles using DBU based task specific ionic liquids and their antimicrobial activity. Eur. J. Med. Chem. 77, 145-154 (2014).

37. El-Zahar, M.I., El-Karim, S.S., Haiba, M.E. and Khedr, M.A., Synthesis, antitumor activity and molecular docking study of novel benzofuran-2-yl pyrazole pyrimidine derivatives. Acta Pol. Pharm. Drug Res. 68, 357-373 (2011). 
38. Girgis, A.S., Hosni, H.M. and Ahmed-Farag, I.S., A convenient regioselective synthesis of 6-amino-2-oxo-3,5-pyridinedicarbonitriles. Z Naturforsch. 58b, 678-685 (2003).

39. Perez, C., Pauli, M. and Bazevque, P., An antibiotic assay by the agar well-diffusion method. Acta Biolo. Med. Exper. 15, 113-115 (1990).

40. Scott, A.C., Laboratory control of antimicrobial therapy In: Collee, J.G., Duguid, J.P., Fraser, A.G. and Marmion, B.P. Mackie and MacCartney Practical Medical Microbiology. (13 ${ }^{\text {th }}$ ed, Churchill Livingstone). 2, 161-181 (1989).

41. Mossman, T., Rapid colorimetric assay for cellular growth and survival: application to proliferation and cytotoxicity assays. J. Immunol. Methods, 65, 55-63 (1983).

42. Hayden, F.G., Cote, K.M. and Douglas, R.G., An antibiotic assay by the agar welldiffusion method. Antimicrob Agents Chemother.17, 865-870 (1980).

(Received 17/ 9/2014; accepted 12/10/2014) 


\section{تحضير مشتقات جديدة المرتبطة برباعي هيدرونفثالين غير

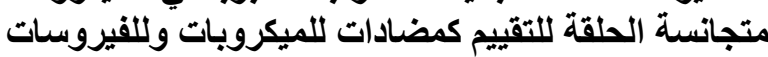

$$
\begin{aligned}
& \text { سمية عبد الكريم(ا)، رشا جوهر(()، مجدة هيبة(أ-ب)، مجدي الزهار(ا)، غادة عواد(ج) } \\
& \text { و علا بجاتو (د) عاريم }
\end{aligned}
$$

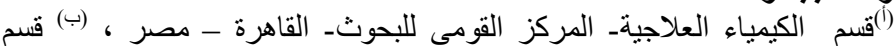

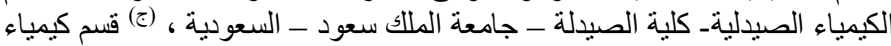

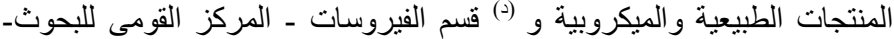

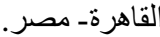

يتناول هذا البحث تفاعل المركب البادئ 2-سيانو-ن"-(3،2ثنائي هيدرونفتالين-

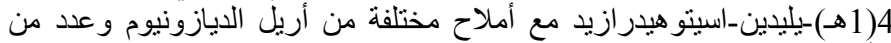

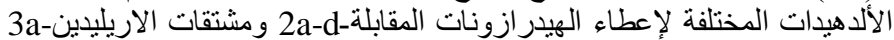

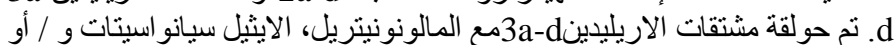

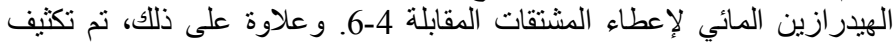

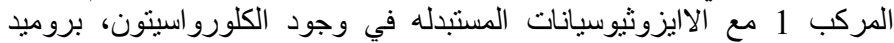

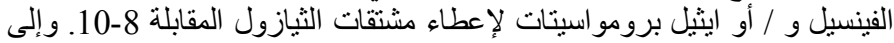

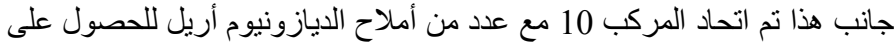

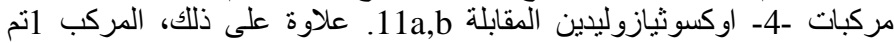

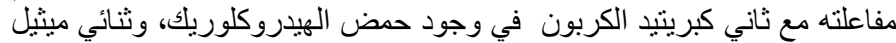

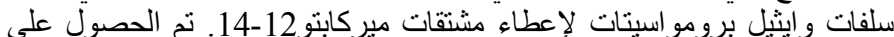

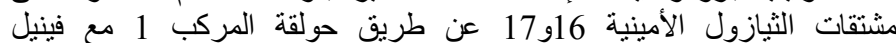

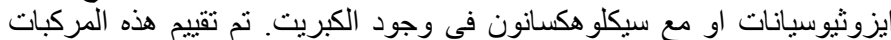
المحضرة حديثا من حيث النشاط كمضادات للميكروبات و للفيروسات. 